\title{
Zur Korrelation der Glazialfolgen im Saale-Komplex Nord- und Mitteldeutschlands am Beispiel des Tagesbaus Jänschwalde in Brandenburg ${ }^{1}$
}

\author{
WERNER NOWEL*)
}

Nowel, W. (2003): Zur Korrelation der Glazialfolgen im Saale-Komplex Nord- und Mitteldeutschlands am Beispiel des Tagesbaus Jänschwalde in Brandenburg. - Eiszeitalter und Gegenwart, 52: 47-83; Hannover.

Keywords: Middle Pleistocene, Saalian Complex, correlation, glacial cycles, warm period, till gravel analysis, till stratigraphy, Lower Lusatia, Brandenburg, North Germany.

Kurzfassung: Das Niederlausitzer Braunkohlerevier ist ein Typusgebiet für die Gliederung des Saale-Komplexes in Ostdeutschland; zwischen Holstein und Eem sind hier drei geschiebeanalytisch unterscheidbare Grundmoränen nachgewiesen (Saale I, Saale II und Saale III sensu CEPEK). Zur Korrelation dieser Lokalgliederung mit NWDeutschland und Polen wird ein Lösungsvorschlag unterbreitet, der in Anlehnung an Richter (1968) und EHLERS (1992) von der Existenz zweier Zyklen mit je zwei Glazialfolgen (Phasen, Vorstößen) ausgeht. Der saale(drenthe-)zeitliche Zyklus begann mit einem westskandinavischen Eisstrom (Glazialfolge Saale 1, "Zeitzer Phase", Haupt-Drenthe, Till-Typ S I) und endete nach Verlagerung der Eisscheide mit einem ostbaltischen Eisstrom (Glazialfolge Saale 2, "Leipziger Phase"). Die Saale 2-Grundmoräne in diesem Verständnis ist ein ostbaltisch dominierter Till, der in Ostdeutschland dem Typ S II sensu CEPEK entspricht oder nahe kommt, in NWDeutschland und den Niederlanden durch die Rote Drenthe-Moräne repräsentiert wird. Der warthezeitliche Zyklus begann mit einem erneuten westskandinavischen Eisstrom (Glazialfolge Warthe 1, "Lausitzer Phase"), dessen maximale Ausdehnung im Wesentlichen mit dem Warthe-Stadium im Sinne von WOLDSTEDT identisch ist, im Nordwesten aber die Lamstedter und Altenwalder

\footnotetext{
${ }^{1}$ Erweiterte Fassung eines Vortrages zum Symposium "Quartär-Stratigraphie: Methoden - Gliederungen Korrelationen" der Geowissenschaftler in Berlin und Brandenburg e.V. am 12. Juni 1999 an der Technischen Universität Berlin.

*) Anschrift des Verfassers: Dipl.-Geol. W. Nowel, Sanzebergstraße 4, D-03042 Cottbus.
}

Endmoränen mit einschließt. Seine Grundmoräne ist ein Till vom Typ S III sensu CEPEK, in Hamburg und Schleswig-Holstein als Niendorf- bzw. Kuden-Till bezeichnet, in Niedersachsen abweichend als "Drenthe 2-Till" interpretiert. Den Abschluß des warthezeitlichen Zyklus bildete nach Verlagerung der Eisscheide wieder ein ostbaltischer Eisstrom (Glazialfolge Warthe 2, „AltmarkPhase"), der zur Ablagerung des Hennstedt-Tills in Schleswig-Holstein, des Fuhlsbüttel-Tills in Hamburg und des Vastorf-Tills in Niedersachsen (den man dort als einzigen Warthe-Till betrachtet) führte. In Ostdeutschland sind ihm Teile des S II-Tills sensu CEPEK zuzurechnen, wozu sicher der rote Altmärker Geschiebemergel gehört. Eine Analyse des Kenntnisstandes von Russland bis Nordwestdeutschland belegt zwischen dem saalezeitlichen und dem warthezeitlichen Vereisungszyklus die Existenz einer Wärmeperiode, deren klimastratigraphischer Rang (interglazial oder nur boreal) noch nicht durchgängig geklärt ist. Zwischen den einzelnen Phasen der Vereisungszyklen (Saale 1/Saale 2, Warthe 1/Warthe 2) wird kein Spielraum für warmzeitliche Entwicklungen eingeräumt.

[Correlation of the glacial sequences of the Saalian Complex in North and Central Germany - the example of the Jänschwalde opencast mine in Brandenburg]

Abstract: The Lower Lusatian lignite mine district is a type area of Saalian Complex stratigraphy of East Germany; between Holsteinian and Eemian Interglacial three tills are proved here, which can be differenciated by till gravel analysis (Saalian I, Saalian II and Saalian III sensu CEPEK). For correlation of this local stratigraphical division with Northwest Germany and Poland, following the conception of Richter (1968) and Ehlers (1992), an answer is proposed, which is based on the existence of two cycles, which again are built of two glacial sequences (phases, ice advances). The Saalian (Drenthian) cycle began with a West Scandinavian ice stream (glacial sequence Saalian 1, "Zeitz Phase", Main Drenthian, till type S I) and, after displacement of the ice divide, it was finished by an East Baltic ice stream (glacial sequence Saalian 2, "Leipzig Phase"). The Saalian 2 till, in this understanding, is an East Baltic dominated till, which in East Germany is identical or similar to the till type S II 


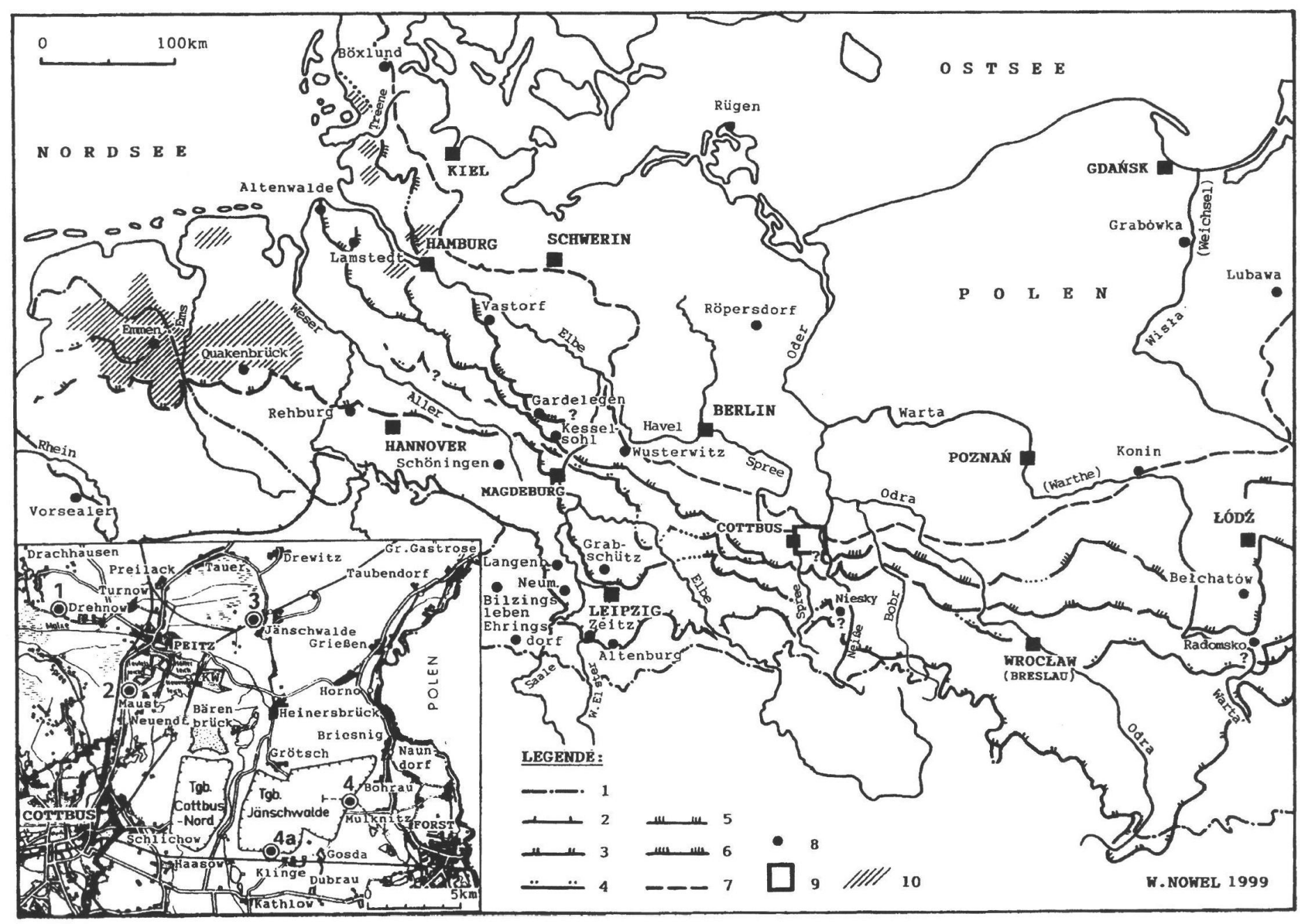


sensu CEPEK, but in Northwest Germany and the Netherlands it is represented by the red Drenthian till. The Warthian cycle began with a new West Scandinavian ice stream (glacial sequence Warthian 1, "Lausitz Phase"), the glacial maximum extent of which is almost identical with the Warthe Stade according to WOLDSTEDT, but in the Northwest it includes the Lamstedt and Altenwalde end moraines. The Warthian 1 till is of the type S III sensu CEPEK, in Hamburg and Schleswig-Holstein it is called Niendorf till and Kuden till, but in Niedersachsen, contrary to that, it is interpreted as "Drenthe 2 till". After the displacement of the ice divide, the finish of the Warthian cycle was again characterised by an East Baltic ice stream (glacial sequence Warthian 2, "Altmark Phase"). It has deposited in Schleswig-Holstein the Hennstedt till, in Hamburg the Fuhlsbüttel till and in Niedersachsen the Vastorf till (which in this country is respected as the only Warthian till). In East Germany parts of the S II till sensu CEPEK belong to it, in any case the red Altmark till. The analysis of knowledge from Russia to Northwest Germany demonstrates the existence of a warm period between the Saalian and the Warthian glacial cycle, but its climatestratigraphical position (interglacial or boreal only) is not clear on all localities.

Abb. 1: Übersichtskarte mit den Vereisungsgrenzen im nördlichen Mitteleuropa (Grundkarte nach LiedTKE 1981 und EHLERS 1992).

1 - Elster max.; 2 - Saale 1 max.; 3 - Saale 2 max.; 4 - Saale 2 Rückzugsstaffel; 5 - Warthe 1 max.; 6 - Warthe 2 max.; 7 Weichsel max.; 8 - wichtige Lokalitäten; 9 - Lage der Nebenkarte Cottbus-Jänschwalde; 10 - Verbreitung der Roten DrentheMoräne.

Nebenkarte: 1 - Profil Drehnow-Drachhausen (nach HellwiG 1975); 2 - Profil Maust 1504/71; 3 - Profil Jänschwalde 9409/95; 4 - Profil Tagebau Jänschwalde Ostrandschlauch (mit Spurlinie des geol. Schnittes Abb. 2); 4a - Südrandschlauch am Bahnhof Klinge.

Fig. 1: General map which demonstrated the extents of the Quaternary Glaciations in Northern Central Europe (Basic map according to LieDTKE 1981 and EHLERs 1992).

1 - maximum extent of the Elsterian Glaciations; 2 - maximum extent of Saalian 1; 3 - maximum extent of Saalian 2; 4 recessional step of Saalian 2; 5 - maximum extent of Warthian 1; 6 maximum extent of Warthian 2; 7 - maximum extent of the Weichselian Glaciation; 8 - important locations; 9 - position of the inset map Cottbus-Jänschwalde; 10 - area of the red Drenthian till.

Inset map: 1 - geologic profile of Drehnow-Drachhausen (according to HeLlwig 1975); 2 - geologic profile of the borehole Maust 1504/71; 3 - geologic profile of the borehole Jänschwalde 9409/95; 4 - geologic profile of the old eastern end slope of the Jänschwalde opencast lignite mine (with line of the profile section fig. 2); $4 \mathrm{a}$ - old southern end slope of the mine near the railway station of Klinge.
Between the single phases or ice advances of the glacial cycles (Saalian 1 to Saalian 2, Warthian 1 to Warthian 2) the existance of warm periods is not likely.

\section{Vorbemerkungen}

Die Schaffung einer einheitlichen Gliederung für den Saale-Komplex in Nord- und Mitteldeutschland gehört zu den viel diskutierten Problemen der Quartärstratigraphie. Während für den Zeitabschnitt vom Holstein-Interglazial s.str. bis zum Saale-Frühglazial sich die Auffassungen weitgehend angenähert haben, bestehen in Bezug auf die klimastratigraphische Bewertung und Zuordnung der einzelnen Glaziationen des Saale-Komplexes seit mehreren Jahrzehnten beachtliche Unterschiede in den Auffassungen:

- In Nordwestdeutschland ist noch immer die Drenthe/Warthe-Grenze umstritten, was insbesondere in den unterschiedlichen stratigraphischen Konzeptionen der geologischen Landesämter Niedersachsens, Schleswig-Holsteins und Hamburgs zum Ausdruck kommt.

- In Ostdeutschland ist es bisher nicht befriedigend gelungen, eine praktikable Korrelation zwischen den durch CEPEK begründeten drei kaltzeitlichen Abfolgen des Saale-Komplexes (Saale-Kaltzeit s.str., Fläming-Kaltzeit, Lausitz-Kaltzeit) und dem in den westdeutschen Bundesländern und darüber hinaus in West- und Nordeuropa geltenden Modell mit den stratigraphischen Kategorien Drenthe und Warthe zu finden.

- Und drittens schließlich gibt es in West und Ost gleichermaßen seit WoldSTEDT (1927) ein Ringen um die bis heute nicht eindeutig beantwortete Frage nach dem klimastratigraphischen Rang von Saale i.e.S. (bzw. Drenthe) und Warthe und in diesem Zusammenhang nach dem Rang einer zwischen beiden einzuordnenden Wärmeperiode.

Im Folgenden wird versucht, anhand von Ergebnissen aus dem Niederlausitzer Braunkohlerevier zur Lösung der genannten Probleme beizutragen. Das im weiteren Umfeld der Stadt Cottbus gelegene Revier (Übersichtskarte Abb. 1) nimmt im nordeuropäischen Vereisungsgebiet durchaus eine Schlüsselstellung ein: Die Maximalausdehnung der SaaleVereisung verläuft unmittelbar südlich, das Brandenburger Stadium der Weichsel-Kaltzeit berührt seinen Nordteil und das Warthe-Stadium quert die 
Mitte des Reviers von NW nach SE. Der Braunkohlebergbau hat hier im Laufe seiner mehr als 100-jährigen Entwicklung mit ca. 500000 Erkundungsbohrungen und den mehrere Kilometer langen Tagebauböschungen eine große Anzahl von Fakten auch für die Quartärforschung geliefert. Dieses Gebiet gehört zu den geologisch am besten untersuchten Teilen Mitteleuropas. Seit den Untersuchungen von CEPEK (1967 u.a.) sowie ERD (1973 u.a.) sind im Niederlausitzer Braunkohlerevier zwischen Holstein und Eem zweifelsfrei drei geschiebeanalytisch unterscheidbare Grundmoränen nachgewiesen (Saale I, Saale II und Saale III sensu CEPEK). Sie stellen bis heute die gültige Lokalgliederung in den Lagerstättendateien der Lausitzer Braunkohle Aktiengesellschaft (LAUBAG) dar (Nowel 1996, 1998). Als neutrale Bezeichnung für die Ablagerungen und Bildungen der einzelnen Vereisungen wird auf Vorschlag von CEPEK (unveröff.) der Begriff „Glazialfolge (glacial sequence)“ benutzt.

\section{Der Saale-Komplex im Tagebau Jänschwalde}

Der Tagebau Jänschwalde und sein geologisch sehr gut erkundetes Umfeld (Nebenkarte in Abb. 1) ist ein Typusgebiet für die Ablagerungen des SaaleKomplexes im Niederlausitzer Revier. Während in dem von Nowel \& Cepek (1988), Cepek \& Nowel (1991) sowie LiPPSTREU et al. (1994) beschriebenen Südrandschlauch des Tagebaus am Bahnhof Klinge (4a in der kleinen Karte) die Schichtenfolge stärkere erosive und glazigene Störungsformen aufwies (die auch $\mathrm{zu}$ teilweise falschen Interpretationen durch alle oben genannten Autoren Anlass boten), wurden an den Böschungen des später entstandenen Ostrandschlauchs westlich Mulknitz (4 in der kleinen Karte) die Grundmoränen aller drei Glazialfolgen in nahezu ungestörter Lagerung übereinander aufgeschlossen und waren über mehrere Jahre für Untersuchungen zugänglich. Deshalb wurde dieses Profil im Auftrag der LAUBAG-Hauptverwaltung sowohl den Teilnehmern der DEUQUA-Exkursion A 1 am 16.9.1994 als auch den Teilnehmern der INQUA-Exkursion B 45 am 11.8.1995 vorgeführt. Für eine erneute Exkursion der "Geowissenschaftler in Berlin und Brandenburg e.V." am 11.6.1999 wurde der Aufschluß nochmals aufgeschürft. Seit dem Frühjahr 2000 wird er mit Vorschnittmassen des Tagebaus verkippt, ist also nicht mehr existent. Eine Gesamtansicht der quartären Schichtenfolge in der Bohrauer Rinne und dem angrenzenden Tagebaufeld am Ostrandschlauch gibt der geologische Schnitt in der Abbildung 2, und zwar:

- über elsterzeitlichem Geschiebemergel und glazilimnischen Bildungen der Rinne einen sehr mächtigen Saale I-Till (g SI), dessen obere $15 \mathrm{~m}$ an der Tagebauböschung freigeschnitten und weitere ca. $20 \mathrm{~m}$ später in einer tiefen Schlucht freigespült worden sind;

Abb. 2: Geologischer Schnitt durch die Tagebauböschung am Ostrandschlauch und die Dubrau-Bohrauer Rinne (Darstellung 10-fach überhöht) W. Nowel 1994.

Erläuterung der quartären Schichtenfolge: Strich-Punkt-Linie Quartärbasis; glEI-II - glazilimnische Sande zwischen Elster I und II; gEII-Grundmoräne Elster II (Geschiebemergel); glEIIn glazilimnische Feinsande und Schluffe als Elster II-Nachschüttbildungen; gfSIv - glazifluviatile Saale I-Vorschüttbildungen (Kies, Sand); gSI - Grundmoräne Saale I (Geschiebemergel); gfSIn - glazifluviatile Saale I-Nachschüttbildungen (Kies, Sand); gISIIv - glazilimnische Feinsande und Bänderschluffe als Saale IIVorschüttbildungen; gSII - Grundmoräne Saale II (Geschiebemergel und -lehm); fSII/III - Tranitzer Fluviatil (Kies, Sand, Mudden); gSIII - Grundmoräne Saale III (= Warthe 1, Geschiebemergel und -lehm); liEe - Eem-Interglazial von Weißagk (Schluff, Mudde, Feinsand); gfWlu - glazifluviatile Kiese und Sande im Baruther Urstromtal (Älterer Baruther Urstrom nach MARCINEK 1961); gf-fW - glazifluviatile (Jüngerer Baruther Urstrom) und fluviatile Sande (Periglazial bis Holozän) im Baruther Urstromtal; D - Binnendünen (Periglazial bis Holozän).

Fig. 2: Geological profile-section into the old eastern end slope of the Jänschwalde opencast lignite mine and the deep Pleistocene erosion channel structure of DubrauBohrau (Vertical exaggeration 10:1) Author: W. NoweL 1994.

Explanation of the Quaternary sequence: Line point line - sole of the Quaternary sequence (base of Quaternary); glEI-II - glacilimnic sands between Elsterian I and II; gEII - Elsterian II till; gIEIIn - glacilimnic fine sands and silts, subsequent sediments of Elsterian II; gfSIv - glaciofluviatile gravels and sands, initial sediments of Saalian I; gSI - Saalian I till; gfSIn - glaciofluviatile gravels and sands, subsequent sediments of Saalian I; gISIIv glacilimnic fine sands and banded clay, initial sediments of Saalian II; gSII - Saalian II till, partly weathered to loam; fSII/III - Tranitz Fluviatile (gravels, sands and muds); gSIII - Saalian III (= Warthian 1) till, partly weathered to loam; liEe - Eemian Interglacial of Weißagk (silt, mud, fine sand); gfWlu - glaciofluviatile gravels and sands of the Baruthian ice-marginal valley (older Baruthian melt water runoff, according to MARCINEK 1961); gf-fW - glaciofluviatile (younger Baruthian melt water runoff) and fluvial sands (periglacial of Weichselian up to Holocene) of the Baruthian ice-marginal valley; D - inland dunes (periglacial of Weichselian up to Holocene). 


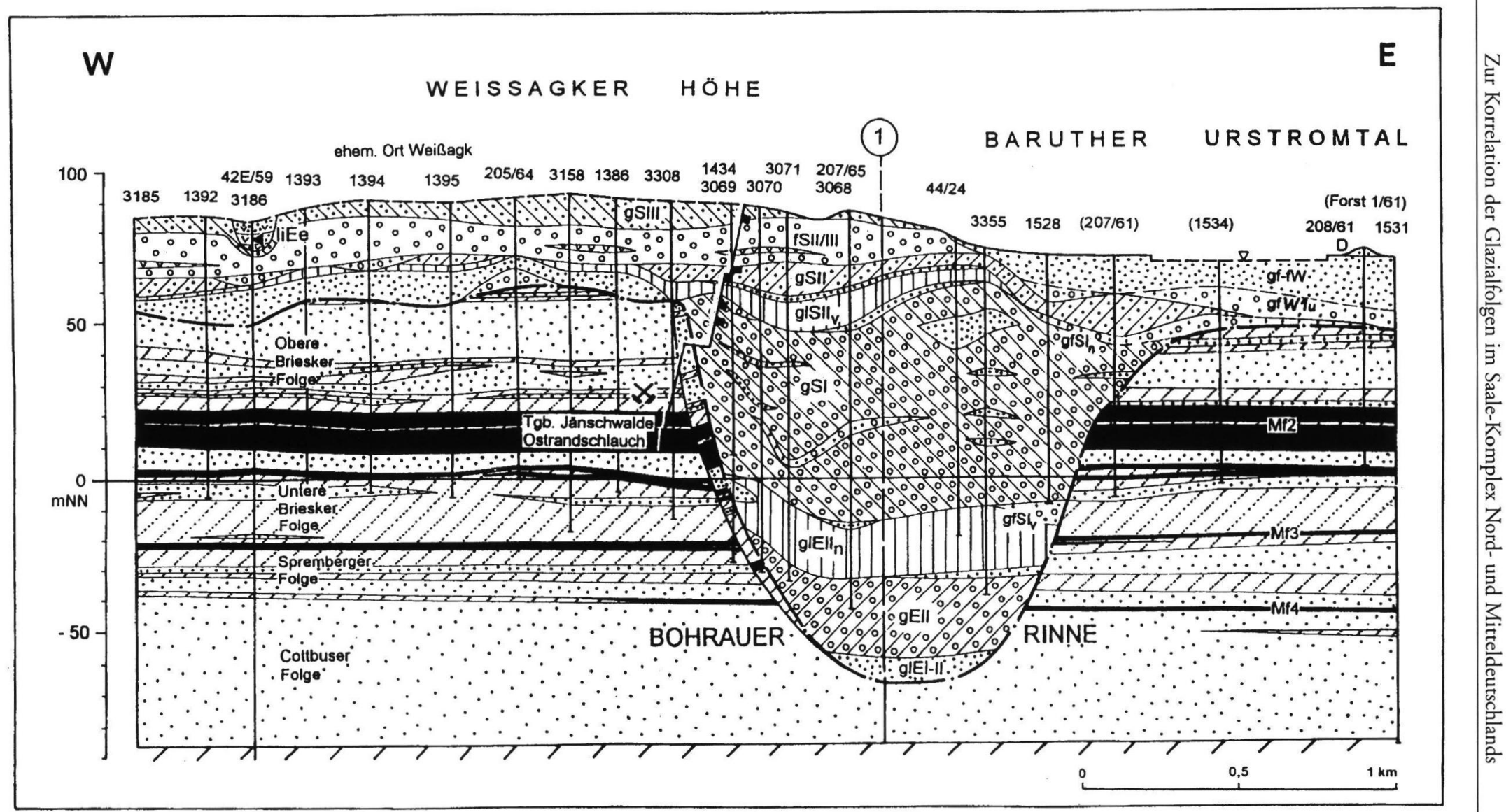


- darüber Bänderschluff und glazilimnischen Feinsand sowie den an der Böschung $6 \mathrm{~m}$, in Bohrungen bis $12 \mathrm{~m}$ mächtigen Saale II-Till (g SII); - darüber das hier 15 m mächtige Tranitzer Fluviatil, von Heluwig (1975) als intrasaalezeitlicher Schotterkörper der Lausitzer Neiße mit Muddelagen nachgewiesen;

- und darüber schließlich den an der Böschung etwa $6 \mathrm{~m}$, im überbaggerten Teil der Weißagker Hochfläche um $10 \mathrm{~m}$ mächtigen Saale III-Till (g SIII).

Ein im Rinnentiefsten kreuzender Schnitt 1 verläuft über die Ortslage Dubrau hinaus nach Süden und bestätigt anhand von 24 tiefen Bohrungen diese Schichtenfolge auf ca. $8 \mathrm{~km}$ Länge. Detaillierte Beschreibungen der Schichtenfolge einschließlich Kleingeschiebeanalysen der drei Geschiebemergel sowie Geröllanalysen des Tranitzer Fluviatils erfolgten durch Hellwig, Kühner \& Nowel (1994: $156,160,164-166)$ und darauf basierend auch in SCHirmer (1995: 370-372) sowie Nowel (1996).

Die stratigraphische Position des Profils als wirklich zum Saale-Komplex gehörig ist im Hangenden eindeutig definierbar durch die Eem-Vorkommen von Weißagk und Klinge. Das Eem der Bhg. 42 E/59 (Pollenanalyse: K. ERD) wurde 1988 vom Tagebau überbaggert; es war in einer Hohlform in die gleiche Saale III-Grundmoräne der Weißagker Hochfläche eingesenkt, die am Ostrandschlauch noch ansteht (Abb. 2). Das heute noch zugängliche berühmte Klinger Eem (Pollenanalyse: M. SEIFERT) wird ebenfalls von Grundmoräne mit Saale III-Geschiebespektrum und Tranitzer Fluviatil unterlagert, über die Tagebauböschungen und ein dichtes Bohrnetz ist die lithostratigraphische Korrelation mit dem Ostrandschlauch möglich. Die Abgrenzung zum Holstein-Interglazial im stratigraphischen Liegenden ist nicht auf so direkte Weise möglich, aber anhand der folgenden Argumente doch sehr wahrscheinlich:

a) Im ausgespülten Saale I-Till des Ostrandschlauchs wurden 1997 zwei bestimmbare Exemplare von Viviparus diluvianus KUNTH gefunden; das Saale I-Inlandeis hat also sehr wahrscheinlich Holstein-Interglazial der Paludinenbank aufgearbeitet, der Till ist demnach jünger als Holstein.

b) Das sichere Holstein-Interglazial der Bhg. 1504/71 (Pollenanalyse siehe ERD 1994a; Nr. 2 in der Übersichtskarte und in der Abb. 3) kann aufgrund eines 1995 durchgeführten Bohrprogramms lithostratigraphisch nach $\mathrm{NE}$ zu den Orten Jänschwalde und Drewitz verfolgt werden (Nr. 3 in Karte und Abb. 3, hier als Beispiel Bhg. 9409/95). Hier wird das Fluviatil des Holstein sensu lato von einem Geschiebemergel überlagert, der über das Erkundungsbohrnetz mit dem g SI des Kohlefeldes Jänschwalde parallelisierbar ist.

LIPPSTREU (1995: 131) hingegen argumentierte für eine Rückstufung des Tranitzer Fluviatils in die Frühsaalezeit, so dass alle unterlagernden Tills elsterzeitlich wären. Gegen diese Vorstellung sprechen aber neben o.g. Fakten auch die aus der Abbildung 3 ersichtlichen Höhenlagen der unterschiedlich alten Schotterkörper und sich daraus ergebende theoretische Gefällewerte. Eine Verbindung des Oberen Tranitz (Niveau $+72 \mathrm{~m} \mathrm{NN}$ ) mit den echten Frühsaale-Schottern von Jänschwalde und Maust (Basis um $+20 \mathrm{~m} \mathrm{NN}$ ) ergäbe ein Flussgefälle von $5 \mathrm{~m} / \mathrm{km}$, was bei tektonisch ungestörter Lagerung völlig unmöglich ist. Verbindet man die Basis des Oberen Tranitzer Fluviatils der Weißagker Hochfläche mit den von HeLlwIG (1975) ebenfalls als Oberes Tranitz identifizierten Kiessanden von Drehnow und Drachhausen (1 in Abb. 1 und 3), so ergibt das bei $17 \mathrm{~km}$ Entfernung und $15 \mathrm{~m}$ Höhenunterschied einen akzeptablen Wert von $0,9 \mathrm{~m} / \mathrm{km}$. Erinnert sei außerdem daran, dass Hellwig (1975) bereits in einer Bohrung bei Drehnow beide Fluviatilkörper übereinander dargestellt hat, getrennt durch Saale II-Grundmoräne und Saale I-Glazifluviatil (Säule 1 in Abb. 3).

Im Weiteren wird davon ausgegangen, dass es sich bei den drei Tills des Profils Ostrandschlauch Jänschwalde tatsächlich um Bildungen der drei saalezeitlichen Glazialfolgen Saale I, Saale II und Saale III im Sinne von Cерек handelt. Sie sind mit jeweils vergleichbarem Kleingeschiebespektrum im gesamten Niederlausitzer Braunkohlerevier anzutreffen, jedoch nur selten in so ausgeprägter Superposition.

\section{Zur regionalgeologisch-stratigraphischen Nutzbarkeit der Geschiebespektren von Grundmoränen}

Die von CEPEK in den 60er Jahren entwickelte Methode zur Kleingeschiebeanalyse von Grundmoränen geht in ihrer stratigraphischen Interpretation 


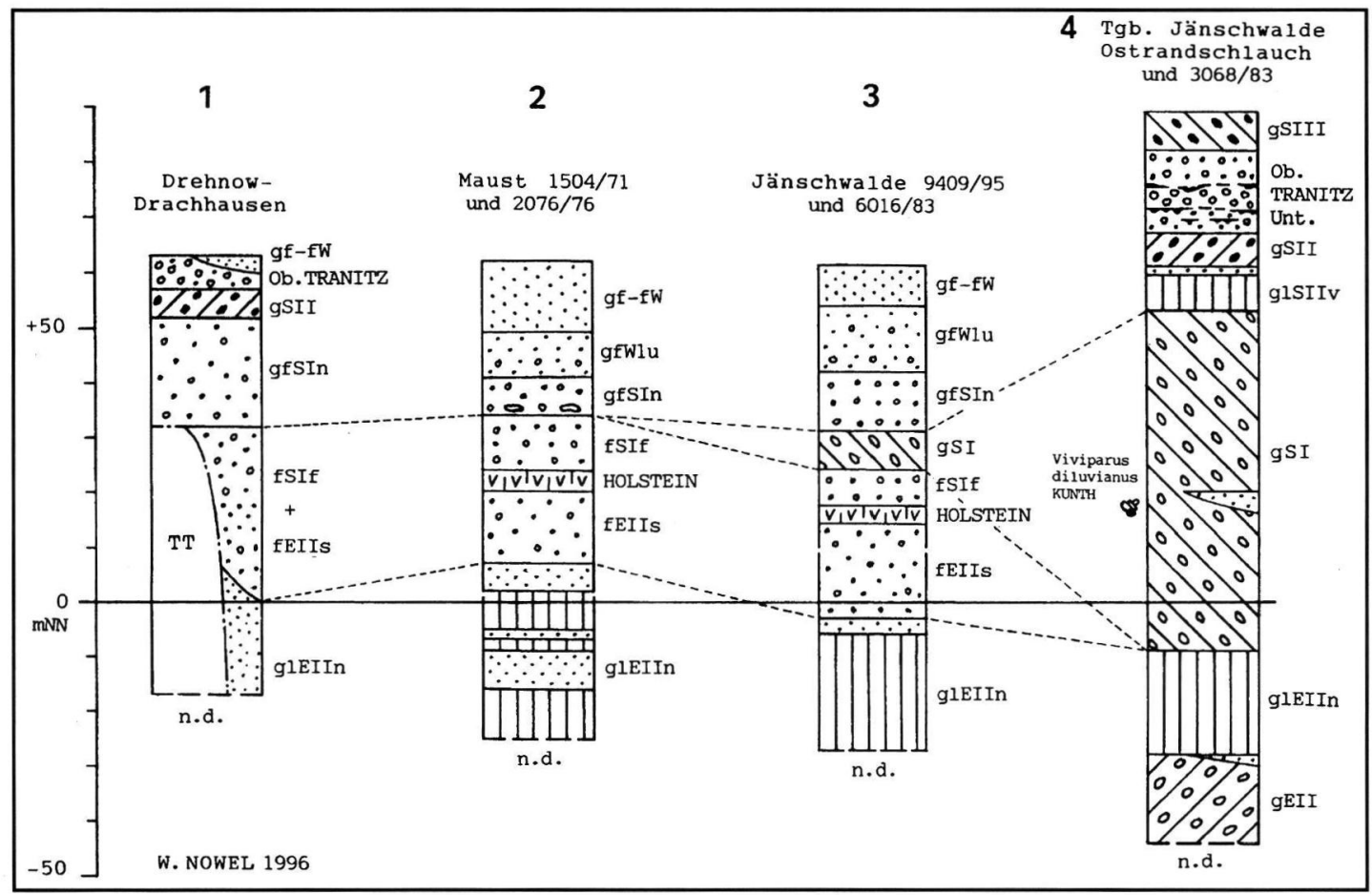

Abb. 3: Säulenprofile zur Stratigraphie des Saale-Komplexes im Gebiet Cottbus-Forst.

Lage der Profile siehe Nebenkarte in Abb. 1. Erläuterung der stratigraphischen Kurzzeichen siehe Abb. 2. Ergänzung: fEIIs - Fluviatil des Elster II-Spätglazials; fSIf - Fluviatil des Saale I-Frühglazials.

Fig. 3.: Geologic pillar sections to demonstrate the stratigraphy of the Saalian Complex of the area of Cottbus-Forst. Geographical position of sections see enset map in Fig. 1. Explanation of the stratigraphical symboles see Fig. 2. Supplement: fEIIs - fluvial sediments of the Elsterian II late glacial; fSIf - fluvial sediments of the Saalian I early glacial.

von der empirisch ermittelten Tatsache aus, dass in den verschiedenen Vereisungen wechselnde Hauptstromrichtungen der skandinavischen Inlandeismassen über den Ausstrichen präkänozoischer Gesteine im skandinavisch-baltischen Raum zu jeweils unterschiedlichen, ganz charakteristischen Inhalten an Ferngeschieben führten (CEPEK in SCHIRMER 1995: 368). Die in der TGL 25232 "Analyse des Geschiebebestandes quartärer Grundmoränen" (1971) erläuterte und zur Anwendung empfohlene Verfahrensweise hat sich zur Unterscheidung der drei Geschiebemergelhorizonte des Saale-Komplexes im Niederlausitzer Revier bewährt; als Beweis mögen die Beispiele in der Abbildung 4 dienen, wo insbesondere im $\mathrm{g}$ SII die ostbaltische Zusammensetzung mit häufigen Dolomiten hervorgehoben ist.

Diese CEPEKsche Methode "ist geeignet, sich nach Anpassung an die regionalen Gegebenheiten und Vervollkommnung im gesamten europäischen
Vereisungsgebiet durchzusetzen" (ERD 1994b: 127). Als Befürworter derselben kann man davon ausgehen, dass das Kleingeschiebespektrum eines Eisschilds über größere Entfernungen - etwa im Gebiet von Schleswig-Holstein bis Brandenburg eine vom Grundsatz her ähnliche Zusammensetzung aufweist (also entweder schwedisch dominiert oder ostbaltisch dominiert), ohne dabei allerdings völlige Identität bei bestimmten Komponenten und Quotienten zu fordern und lokale Schwankungen zu ignorieren. Andere Autoren lehnen diese Vorstellung $a b$ und gehen von einer mehr oder weniger chaotischen Geschiebeführung innerhalb eines Eisschildes aus.

Neben der sachlichen Bewertung des Geschiebeinhalts der einzelnen Grundmoränen hat die Modellvorstellung zur regionalgeologisch-stratigraphischen Interpretation derselben eine große Bedeutung. Sie ist nicht frei von subjektiven und hypothetischen Einflüssen. CEPEK stellte sein auf 
Schönfeld, A1

Seese-Ost, A11

Jänschwalde (Klinge), Profil 3: 1,0-1,5m

Bhg. Kahsel 1/86;25m

Bhg. Jocksdorf $33 / 85 ; 10 \mathrm{~m}$

Seese-Ost, A8

Bhg. Drachhausen 6/74:5,4-6,4m

Jänschwalde (Klinge), östl.Eem: 0-0,5m

Bhg. südl. Roggosen;6,0-7,0m

Bhg. Trebendort 2/88;29-30m

Bhg. Jocksdort Sim 3/85;21,4-21,8m

Seese-Ost, A2

Seese-OsI, A3

Bhg. NE Gosda; 76,5-77,5m

Bhg. SE Dubrau; $38-40 m$

Bhg. ESE Jethe; $79-80 \mathrm{~m}$

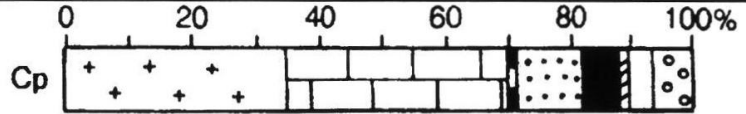

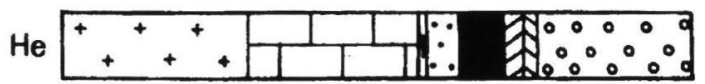

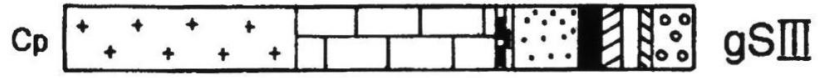

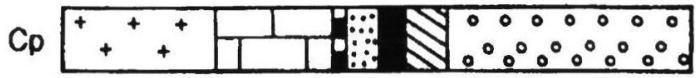

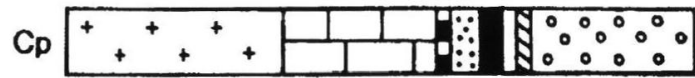
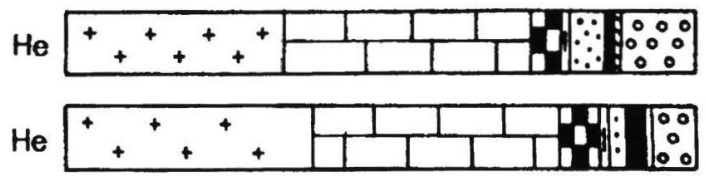

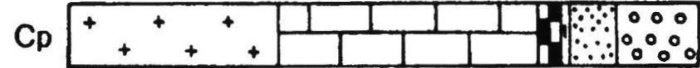
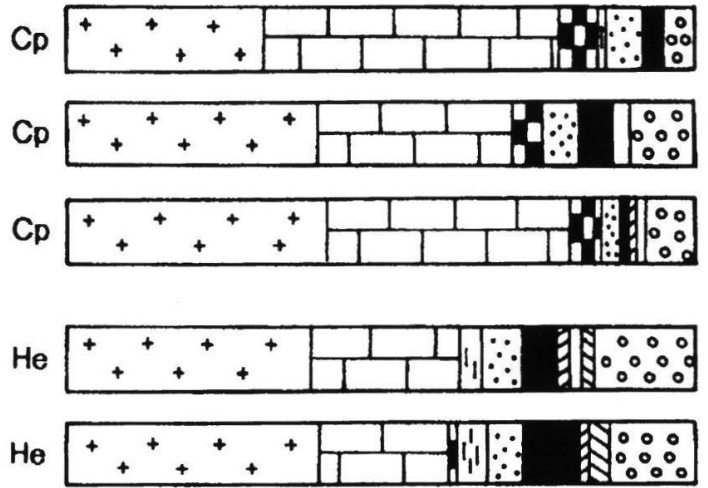

$\mathrm{Cp}$
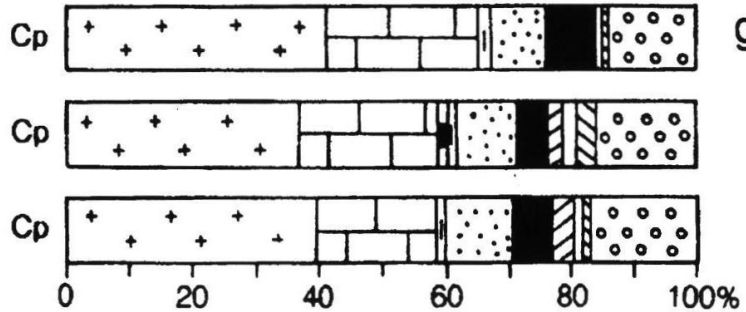

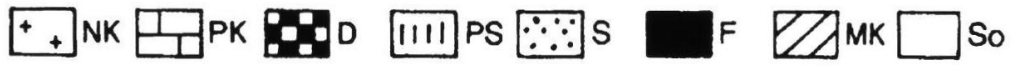
südl. \&ido 
Basis der Kleingeschiebeanalyse erarbeitetes Modell der Grundmoränenstratigraphie auf dem VI. INQUA-Kongreß 1961 in Warschau und auf der 12. DEUQUA-Tagung 1964 in Lüneburg vor und legte - in den Folgejahren weiter präzisiert - für den Saale-Komplex NE-Deutschlands einen dreifachen, gleichrangigen Kaltzeit/Warmzeit-Wechsel zugrunde:

\section{A. Saale I-Glaziation (Saale-Kaltzeit i.e.S.)} mit Hauptstromrichtung aus dem schwedischen Raum.

B. Rücktauen des Eises bis Skandinavien, in NEDeutschland Entwicklung einer Wärmeperiode von mindestens interstadialem Rang, die 1964 in Anlehnung an PICARD und LÜTTIG zunächst als Treene (?)- oder Gerdau (?)-Thermomer bezeichnet und 1987 dann mit der Uecker-Warmzeit von Röpersdorf besetzt wurde.

C. Saale II-Glaziation (Fläming-Kaltzeit) mit Hauptstromrichtung aus dem baltischen Raum.

D. Erneutes Rücktauen des Eises bis Skandinavien, in NE-Deutschland Entwicklung einer erneuten Wärmeperiode von diesmal interglazialem Rang, bewiesen durch die Typus-Lokalitäten der Rügen-Warmzeit auf Kap Arkona und Hiddensee. In der Niederlausitz durch Hellwig (1975) Nachweis des Tranitzer Fluviatils in dieser Position.

E. Saale III-Glaziation (Lausitz-Kaltzeit) mit erneuter Hauptstromrichtung des Inlandeises aus dem schwedischen Raum.
Diese zunächst sehr einleuchtende Modellvorstellung ist in der einfachen Form nicht haltbar, wenn man anderslautende Argumente vor allem nordwestdeutscher Autoren berücksichtigt. So haben unter anderem WOLDSTEDT \& DUPHORN (1974), Jordan (1975), Stephan et al. (1983) sowie Ehlers, MEYer \& Stephan (1984) darauf hingewiesen, daß ostbaltisch geprägte Grundmoränen des CePeKschen Typs Saale II nicht nur in einer, sondern in verschiedenen stratigraphischen Positionen vom späten Elster bis zum späten Weichsel angetroffen wurden. Innerhalb des Saale-Komplexes Nordwestdeutschlands sind seit langem zwei ostbaltisch dominierte Tills bekannt: Die Rote Drenthe-Moräne im Hangenden des Hauptdrenthe-Tills und ein jüngerer Warthe-Till (Hennstedt- und Fuhlsbüttel-Till, Vastorf-Till) im Hangenden der schwedisch dominierten Warthe 1-Moräne. Aus diesen und weiteren Befunden schließt EHLERS (1992) in Anlehnung an Richter (1968), dass wahrscheinlich während jeder der pleistozänen Eiszeiten jeweils ein Vereisungszyklus ablief, der mit einem westskandinavischen Eisstrom begann und nach allmählicher Verlagerung der Eisscheide mit einem ostbaltischen Eisstrom endete. Bereits WOLDSTEDT \& DuphorN (1974: 72) brachten diese Hypothese wie folgt auf den Punkt: "Offenbar wurde das Eis des westskandinavischen Eiszentrums zu Beginn der Eiszeiten durch viel Feuchtigkeit vom Atlantik her besonders gut genährt und konnte daher zuerst in den relativ nahe gelegenen norddeutschen Raum vorstoßen. Mit fortschreitendem Eisaufbau im Lee des skandinavischen Hochge-

Abb. 4: Beispiele für Kleingeschiebeanalysen (nach TGL 25 232) aus dem Saale-Komplex der Niederlausitz. Aus Cepek, Hellwig \& Nowel (1994). Untersuchungen von A.G. Cepek (Cp) und D. Hellwig (He) an Bohr- und Aufschlußproben.

NK - nordisches Kristallin; PK - paläozoische Kalksteine; D - Dolomite bis Dolomitmergelsteine; PS - paläozoische Schiefer (Tonsteine); S - Sandsteine und Quarzite; F - Feuersteine (Flint); MK - mesozoische Kalksteine (insbesondere Kreide u. verkieselte Kreide); So - Sonstige (Pyrit, Phosphorit, Limonit u.a.); Südl. - aufgenommene südliche Flußgerölle (Isergebirgsfeldspäte und anderes südliches Kristallin, Kieselschiefer, Verkieselungen, Achat, Basalt, Erdbrandgestein); Q - Quarz (fast ausschließlich gut gerundet). Im Text werden weiterhin verwendet: Ffr - frischer, unverwitterter Feuerstein; PKgr - grauer paläozoischer Kalkstein; PKr+sz roter und schwarzer paläozoischer Kalkstein.

Fig. 4.: Examples of till gravel analyses (by TGL 25232) of the Saalian Complex of Lower Lusatia. According to CEPEK, Hellwig \& Nowel (1994). Investigations by A.G. CepeK (Cp) and D. HellWIG (He) at borehole and outcrop samples. NK - northern (Scandinavian) cristalline rocks; PK - paleozoic limestones; D - dolomites and dolomitic marl; PS - paleozoic schist stones; S - sandstones and quarzites; F - flints; MK - mesozoic limestones (especially northern cretaceous limestones); Südl. - assimilate southern fluvial componentes (feldspar of Isergebirge and other southern cristalline rocks, siliceous schist, silifications, agate, basalt, baked shale); Q - quartz (predominantly good subroundet). In the text besides in application: Ffr - unweathered flint; PKgr grey paleozoic limestone; PKr+sz - red and black paleozoic limestone. 
birges verlagerte sich die Eisscheide mehr nach Osten. Diese Verlagerung hatte einen verstärkten Eisschub von Ostskandinavien über den Ostseetrog nach Norddeutschland zur Folge."

Das Vorhandensein von zwei ostbaltisch dominierten Tills im Saale-Komplex Nordwestdeutschlands macht nicht nur aus glazio-genetischer, sondern auch aus stratigraphischer Sicht eine Überprüfung des CEPEKschen Modells für NE-Deutschland erforderlich. Hauptfrage: Mit welchem Grundmoränenhorizont NW-Deutschlands ist der "Saale II-Till sensu CEPEK" zu korrelieren?

CEPEK (1965) hatte seine ostbaltische S II-Grundmoräne mit dem nordwestdeutschen Warthe-Stadium korreliert, wobei zur Meinungsbildung wohl auch schon die ebenfalls ostbaltisch geprägte Fuhlsbüttel-Moräne des Hamburger Raumes (GRUBE 1967) eine Rolle spielte. GaUger \& Meyer (1970) sowie Woldstedt \& DUPHORN (1974: 68) griffen diese Korrelation auf: "An der Gleichaltrigkeit der durch die Vastorfer Geschiebegemeinschaft gekennzeichneten, roten Warthe-Grundmoräne in der Lüneburger Heide mit der S 2-Grundmoräne CepeKs ist ... bei der gemeinsamen, extrem ostbaltisch orientierten Geschiebegemeinschaft kaum zu zweifeln". Damit war diese Vorstellung fest begründet und wurde auch von EHLERs, MEYER \& Stephan (1984: 3) sowie Ehlers (1992: 101) im Prinzip noch so vertreten. Sie hatte aber von Anfang an den Nachteil, daß die CePeKsche Glazialfolge Saale III im Westen keinen "Partner" hatte und zusammenhanglos darüber schwebte.

Schon im IGCP-Report Nr. 2 hat CEPEK (1975:72) jedoch seinen Saale II-Till dem nordwestdeutschen Drenthe zugeordnet, wenn auch mit vielen Fragezeichen. Er korrelierte hier ausdrücklich mit Schleswig-Holstein, weil die dortigen Ergebnisse von MenKe (1970) im Früh-Saale (Mehlbek-Kaltzeit und Wacken-Warmzeit) problemlos mit dem ostdeutschen Fuhne und Dömnitz übereinstimmen, aber auch, weil die schwedisch dominierte S IIIGrundmoräne gut mit der ebenso aufgebauten schleswig-holsteinischen Warthe 1-Moräne (Kuden, Niendorf) kompatibel ist. Offen blieb dabei ein westdeutscher "Partner" für den ostdeutschen S IITill ebenso wie ein ostdeutscher "Partner" für den westdeutschen Warthe 2-Till.

Einer Lösung der noch offenen Fragen bringt uns die Tabelle 1 (nach Ehlers 1992) näher, wo die
Rote Drenthe-Moräne NW-Deutschlands als besondere stratigraphische Kategorie hervorgehoben ist und sich als "Korrelationspartner" im saalezeitlichen Vereisungszyklus präsentiert. Entsprechend den in der Tabelle vom Autor vorgenommenen Veränderungen und Ergänzungen ist zu unterstellen, dass es (abweichend von bzw. ergänzend zu CЕРЕК) auch im Saale-Komplex Ostdeutschlands zwei ostbaltische Eisvorstöße gab und demzufolge auch hier zwei ostbaltisch dominierte Tills unterschieden werden müssen: Ein saalezeitlicher "S II Typ Lausitz" und ein warthezeitlicher "S II Typ Altmark". Zu ähnlichen Schlussfolgerungen kommt auch BEHRENDT (1998: 30). Unterstützung findet sich des weiteren in der Feststellung von RüHBERG et al. (1995: 102), dass in Mecklenburg-Vorpommern die „... typische baltische Geschiebegemeinschaft sowohl in Drenthe- als auch in Warthe-Grundmoränen vorkommt."

\section{Versuch einer Korrelation von der Nieder- lausitz bis Schleswig-Holstein und Vergleich mit der Gliederung in Polen}

\subsection{Glazialfolge Saale 1}

Eine Korrelation der Niederlausitzer Glazialfolge Saale 1 (Geschiebemergel g SI = Saale-Kaltzeit s.str. im Sinne von СЕРек) mit der des übrigen norddeutschen Vereisungsgebietes ist einfach, denn sie entspricht nach übereinstimmender Auffassung dem sog. Saale-Hauptvorstoß bzw. Haupt-Drenthe oder Drenthe 1. Der unverwitterte Geschiebemergel beinhaltet im gesamten Verbreitungsgebiet ein schwedisch dominiertes Kleingeschiebeinventar, das im wesentlichen den von CEPEK und Hellwig publizierten Kennwerten entspricht.

Der Saale I-Geschiebemergel des Profils Jänschwalde ist $\mathrm{Ffr}$ - und S-reich $(\mathrm{Ffr} / \mathrm{PK}=0,18-0,34$; $\mathrm{PK}+\mathrm{D} / \mathrm{S}=3,3-5,8)$, NK-reicher und D-ärmer als der $\mathrm{g}$ SII $(\mathrm{NK} / \mathrm{PK}=1,07-1,54 ; \mathrm{NK} / \mathrm{D}=19,0$ 59,0), der Quotient $\mathrm{PKgr} / \mathrm{PK}_{\mathrm{r}+\mathrm{sz}}$ ist mit Werten zwischen 5,7 und 11,3 geringer als im $\mathrm{g}$ SII (HeLLWIG in EISSMANN \& LitT 1994: 160, 166) (Erläuterung der Abkürzungen siehe Abb. 4).

Unterschiedliche (und in den letzten 30 Jahren auch mehrfach wechselnde) Auffassungen gibt es bezüglich der Zuordnung der EIssmannschen „Zeitzer Phase“ und „Leipziger Phase" in der sächsi- 


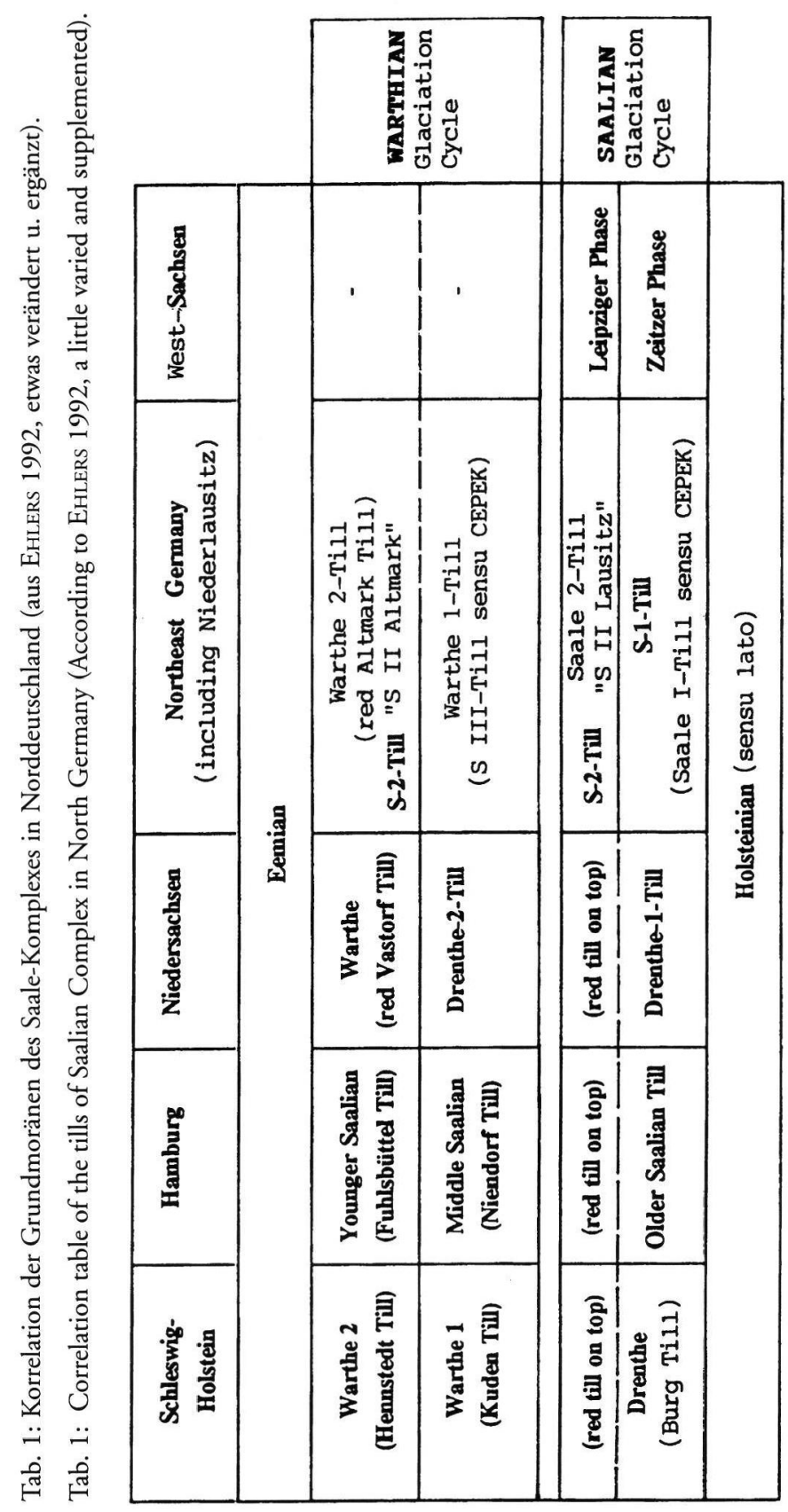

Haupt-Drenthe) zu korrelieren ist. Das bedeutet eine Abkehr von der Auffassung Eismanns (1995, 1997), dass "die ältere bzw. untere SaaleGrundmoräne des Lausitz-Brandenburger Raumes (SI) den Grundmoränen der Zeitzer und Leipziger Phase westlich der Elbe entspricht", und eine Rückkehr zu der in EISSMANN (1975: Abb. 58) dargestellten, in dieser Frage damals mit CEPEK übereinstimmenden Korrelation. Übereinstimmung in dieser Frage besteht auch mit LiTT \& TURNER (1993: 126).

Die flächenhafte Ausdehnung der Glazialfolge Saale 1 ist in den Niederlanden und Deutschland seit langem als Maximalausdehnung der Saaleeiszeit fixiert. In der Oberlausitz wurde von STEDING (1976) sowie Wolf, Steding \& Schubert (1992) eine in den 60er Jahren angenommene Ausdehnung bis Löbau oder gar Oderwitz korrigiert zu einem weiter nördlichen Verlauf im Gebiet zwischen Görlitz und Niesky. Die Saale-Grundmoräne im Tagebau Berzdorf südlich Görlitz schreiben sie einem aus dem polnischen Gebiet herüberreichenden Eislobus zu (dazu Abschn. 4.6).

\subsection{Glazialfolge Saale 2}

Der Saale II-Geschiebemergel von Jänschwalde ist ein durchschnittlicher Vertreter des ostbaltisch dominierten Typs S II im Sinne von Cерек. Er beinhaltet in den Analysen vom Ostrandschlauch (HeLlWIG in EISSMANN \& LitT 1994: 160, 164165) die höchsten Dolomitgehalte der drei anstehenden Saale-Tills, auch

schen Typusregion Leipziger Tieflandsbucht. Auf der Grundlage der geschiebeanalytischen Befunde von Manhenke \& Grosse (1970) sowie A. Múller (1988) muß heute geschlussfolgert werden, dass nur die 1. Saale-Grundmoräne EIssmanns, also nur die Zeitzer Phase, mit der Niederlausitzer Glazialfolge Saale 1 (und damit dem Saale-Hauptvorstoß oder wenn infolge sehr hoher Quarzgehalte der Prozentanteil etwas niedriger erscheint als in anderen Niederlausitzer Profilen. Die Quotientenbildung zeigt deutliche Indikationen: $\mathrm{PK}+\mathrm{D} / \mathrm{S}$ ist deutlich $>5$; NK/PK liegt bei 1; Ffr/PK liegt zwar etwas über 0,1 , aber deutlich niedriger als im Saale I-Till; und NK/D liegt (abgesehen von einem Ausreißer) 
deutlich niedriger als im Saale I- und Saale III-Till (zwar wird der Richtwert $<11$ nur in einer Probe erfüllt, die anderen liegen aber immerhin deutlich unter 18).

Die Maximalausdehnung der Glazialfolge Saale 2 ist im Niederlausitzer Braunkohlerevier durch Nowel (1965: 81) und Cерек (1967: 392) auf der Linie Tröbitz (westlich Doberlug-Kirchhain) - Elsterwerda - Lauchhammer - Hohenbocka/Hoyerswerda fixiert. Die weitere Fortsetzung nach Osten wird in den Stauchmoränen bei Rietschen nördlich Görlitz vermutet, hier fehlt aber eine Bestätigung durch S IIGeschiebemergel. Westlich der Tröbitzer Endmoräne, im westelbischen sächsischen Gebiet, ist die Fortsetzung in dem von Cерек (1967: 392) bereits als "mögliche Maximalausdehnung der Saale IIVereisung" dargestellten Verlauf über die Eilenburger zur Tauchaer und Petersberger Randlage anzunehmen (Abb. 1).

Nach den bereits erwähnten Geschiebeanalysen von Manhenke \& Grosse (1970: 918) weisen die Moränenbänke der Leipziger Phase generell eine ostbaltisch geprägte, dem CePEKschen "Saale IITyp" nahe kommende Zusammensetzung des Kleingeschiebeinhalts auf: "Die sechs untersuchten Proben der zweiten Saale-Grundmoräne enthielten 0,3-3,0 \%, im Mittel 1,3 \% Dolomit. Die nach A.G. Серек (1969) zu bildenden NK/D-Koeffizienten zeigen mit durchschnittlich 23,5 zwar die niedrigsten Werte aller Grundmoränen, jedoch wurde nur in einem Fall mit 11,0 der von СЕРеK zur Abgrenzung der S 2-Grundmoräne in den Bezirken Potsdam, Frankfurt und Cottbus angegebene Grenzwert erreicht. Da aber die außerdem ... zur Charakteristik der S 2-Grundmoräne genannten Quotienten F/PK und NK/PK mit durchschnittlich 0,11 bzw. 0,99 CEPEKs Grenzwerten für den mittleren und nördlichen Teil der DDR von $<0,1$ bzw. $<1,0$ sehr nahe kommen, besonders relativ zu den anderen Grundmoränen, ist zu vermuten, dass unsere zweite Saale-Grundmoräne der S 2-Grundmoräne ... entspricht."

An dieser Stelle sei an die auch im Jänschwalder Profil erhöhten NK/D-Werte erinnert und außerdem darauf verwiesen, daß ZIERMANN (in CEPEK et al. 1975: 1059) stellenweise in Westbrandenburg NK/D-Werte von 15 bis $30 \mathrm{im} \mathrm{g} \mathrm{SII} \mathrm{ermittelt} \mathrm{hat.}$ Die im Erkundungsgebiet Hatzfeld z.T. auflagernde dritte Saale-Grundmoräne "wurde im Habitus ... nicht von der des 2. Vorstoßes unterschieden" und "konnte nur im Verbreitungsgebiet des Breitenfelder Horizontes abgetrennt werden." Sie stellt wohl nur eine lokale Oszillation der Leipziger Phase dar. Vergleichbare Schlussfolgerungen wie MANHENKE \& Grosse (1970) zog auch CEPEK aus nicht publizierten Untersuchungen vom benachbarten Tagebau Breitenfeld 1985. A. Mưller (1988) hat Geschiebeanalysen aus dem Gebiet zwischen Dessau, Jessen/Elster und Riesa verarbeitet und kommt im Prinzip zu ähnlichen Ergebnissen. Unter diesen Umständen sollte es heute keinen grundsätzlichen Zweifel mehr daran geben, dass die Grundmoränen der westelbischen Leipziger Phase EIssmanns auf den gleichen Eisvorstoß zurückzuführen sind wie die Saale IIMoräne des ostelbischen Niederlausitzer Raums.

Die Bad Schmiedeberger Stauchmoräne ordnet sich in eine Rückzugsstaffel dieses Saale 2-Vorstoßes oder Leipziger Vorstoßes ein, die nach SE über Jessen/Elster, Lebusa und Hennersdorf verfolgt werden kann, nach NW über die südlichen FlämingStaffeln bis zu Glapas Plankener Randlage nördlich Magdeburg (also den "nördlichen Zug des FlämingGlazials" bei CEPEK [1967: 392] repräsentiert).

Über die Petersberger Randlage setzt sich der Leipziger Vorstoß bis zur Calvörder Randlage nordwestlich Magdeburg fort, die Existenz zweier saalezeitlicher Grundmoränen (Hauptvorstoß und Petersberger Vorstoß) hatte hier schon RUsKe (1965) nachgewiesen. Auch in der Letzlinger Heide beschrieb GlaPA (1970) zwei Drenthe-Geschiebemergel aus dem Liegenden der Warthe-Serie. In der nördlich anschließenden Altmark gliedert v. PoBLOzKI (1995) nur eine Drenthe-Moräne aus, die er schon 1972/73 auf den Lithofazieskarten seines Gebietes als "g S (Grundmoränen SI oder S II ungegliedert)" zusammengefaßt hatte. Auf den Blättern Klötze und Stendal findet man analysierte Geschiebemergel mit S I- und S II-Spektrum in unterschiedlichen Teufen und Mächtigkeiten. Auf Blatt Stendal wurde in drei Bohrungen g SII über gSI dokumentiert, davon zweimal mit sandigkiesigem Zwischensediment und einmal direkt aufeinander liegend. V. PoвLOzKI (1995) favorisiert eine solche Vereinigung beider Moränenbänke für die Altmark und hält ihr getrenntes Auftreten bei Stendal für eine lokale Erscheinung. Die Tendenz zur überwiegend getrennten Lagerung setzt sich aber in Mittelbrandenburg generell fort, wie die 
regionalen Schnitte bei CEPEK et al. (1975) beweisen. Weiter im Norden Brandenburgs und in Mecklenburg-Vorpommern ist ein Zusammengehen der beiden Drenthe-Geschiebemergel zu einem Moränenkörper durchaus denkbar.

Mit Sicherheit ist es so in den Niederlanden, dem westlichen Niedersachsen, in Hamburg und Schleswig-Holstein, wo die westskandinavisch dominierte Drenthe-Hauptmoräne von der ostbaltisch geprägten Roten Drenthe-Moräne direkt überlagert wird (EHLERS, Meyer \& Stephan 1984: 20). Die aus der Literatur bekannte Verbreitung der Roten Drenthe-Moräne ist in der Abbildung 1 durch Schraffur kenntlich gemacht. Woldstedt \& Duphron (1974: 67) fassten das vieldiskutierte Phänomen wie folgt zusammen: "Wahrscheinlich handelt es sich um eine abnorme Petrofazies ein und derselben (Drenthe-)Grundmoräne ... Vielleicht entspricht der rote Geschiebelehm auch einem etwas jüngeren Vorstoß des Drenthe-Eises, das über Toteisplatten des vorangegangenen Drenthe-Hauptvorstoßes hinwegglitt." Aufgrund der großen flächenhaften Ausdehnung erscheint die im letzten Satz formulierte Deutungsvariante logischer, zumal ZandSTRA (1976) nach gründlichen Detailuntersuchungen auch bei direkter Aufeinanderlagerung Beweise zusammentragen konnte, die "auf die Wirkung zweier unterschiedlicher Gletscher hinzeigen. Dazwischen lag eine Zeit des Eisrückzugs; Ablagerungen aus dieser Zeit sind nicht erhalten." Aufgrund seiner Lage zum Hauptverbreitungsgebiet der Roten Drenthe-Moräne ist es nicht abwegig anzunehmen, dass der bekannte Endmoränenzug der Rehburger Phase die Maximalausdehnung des Saale 2-Vorstoßes in Nordwestdeutschland markiert, wie schon von LiedTKE (1981: 197) angedeutet. Diese Deutung stellt allerdings altbewährte niedersächsische Positionen in Frage (zuletzt Caspers et al. 1995). Sie könnte aber sowohl die von KeLler (1953), MEyer (in SCHIRMER 1995: 637) und anderen beschriebene Sachlage des Vorhandenseins von Drenthe-Geschiebemergel auf den Endmoränen erklären als auch die von Mensching (1969) hervorgehobenen frischen morphologischen Formen begründen, die zu der Hypothese einer überfahrenen frühen DrentheRandlage im Widerspruch stehen. Prinzipielle Übereinstimmung besteht mit ZaGWIJN \& STAALDUIN (1975), die in den Niederlanden diese Randlage einer Rückzugsphase des Drenthe-Eises zuordnen.

\subsection{Zusammenfassung zum saale-(drenthe-) zeitlichen Vereisungszyklus}

1. Das Sediment des westskandinavischen, nördlichen Eisstroms (= Glazialfolge Saale 1) ist in NWDeutschland der "normale" Drenthe-Till, in Sachsen-Anhalt und Westsachsen die 1. SaaleGrundmoräne ("Zeitzer Phase") und in der Niederlausitz der Saale I-Till sensu CEPEK.

2. Das Sediment des ostbaltischen Eisstroms (= Glazialfolge Saale 2) ist in der Niederlausitz ein Till vom Typ Saale II sensu CEPEK, in Westsachsen und Sachsen-Anhalt die 2. (und 3.) Saale-Grundmoräne ("Leipziger Phase", "Petersberger Vorstoß") und in Nordwestdeutschland die Rote Drenthe-Moräne.

3. In NW-Deutschland überlagern sich die Tills beider Eisströme direkt. Nach Richter (1968: 265266) "entwickelten hier die vergletscherten Gebiete Toteismassen und Eiskarstphänomene, da der Nachschub aus dem westskandinavischen Eiszentrum nachließ" und "vom ostskandinavischen Eiszentrum her die Eismassen ... in Norddeutschland vorstoßen konnten. Es gelang diesem Eis aber nicht mehr, die Toteismassen ... bis zum derzeitigen äußersten Rand zu aktivieren ... Es kam unter dem aktiven Eis zum Losreißen von großen Detraktionsschollen und an der Grenze zum Toteissaum zu Stau- bzw. Stauchmoränenaufschuppungen. Die Schmelzwasserentwicklung war bei der großen Kälte sehr gering ...

4. In Sachsen-Anhalt, Westsachsen und der Niederlausitz (wie auch Mittelbrandenburg) wurde zwischen beiden Tills eine Folge glazilimnischer und glazifluviatiler Sedimente abgelagert, örtlich sogar fluviatil-glazifluviatile Mischschotter. Hier muß das Eis zurückgetaut gewesen sein, bevor der ostbaltische Eisstrom das Gebiet erneut bedeckte.

\subsection{Glazialfolge Warthe 1 (= Saale III sensu CEPEK)}

Der Saale III-Geschiebemergel des Jänschwalder Profils ist ein normaler Vertreter dieses schwedisch dominierten Till-Typs, der sich durch hohe Gehalte an frischen Feuersteinen, Sandsteinen und paläozoischen Kalken bei geringen Anteilen an Dolomiten und paläozoischen Schiefern auszeichnet. Der Quotient NK/D ist größer 100 bis 
unendlich, der Quotient $\mathrm{PK}+\mathrm{D} / \mathrm{S}$ liegt deutlich unter 5, meist unter 4, und der Gehalt an roten Sandsteinen und Quarziten erreicht mit 3-5\% im $\mathrm{S}$ III-Till sein Maximum. Besonders in den basisnahen Partien ist durch Aufnahme des unterlagernden Tranitzer Fluviatils ein hoher Anteil an lokalem Material (Quarz und Südliche) von 24 bis $54 \% \mathrm{zu}$ beobachten (Hellwig in EisSManN \& LiTt 1994: $160,164)$.

Die südliche Verbreitungsgrenze des Saale III-Tills (= Glazialfolge Warthe 1) ist durch den Endmoränenzug des Niederlausitzer Grenzwalls fixiert, dessen Sander zum Lausitzer Urstromtal entwässern. Er ist Bestandteil jenes Höhenzuges, den Woldstedt $(1927,28)$ als Warthe-Haupteisrandlage definiert hat. Er setzt sich als sog. "Südlicher Landrücken" über den Niederen und Hohen Fläming, die Letzlinger Heide und die Lüneburger Heide nach NW bis in den Raum Hamburg und Schleswig-Holstein fort, nach Osten (östlich der Lausitzer Neiße) zum Trebnitzer Katzengebirge (Wzgórza Trzebnickie) und weiter nach Mittelpolen bei Łódź.

Der Saale III-Geschiebemergel ist in der Niederlausitz die Warthe-Hauptgrundmoräne. Er bildet als 3-10 m, maximal bis $21 \mathrm{~m}$ mächtige kompakte Grundmoräne größere Areale auf den Hochflächen im Hinterland des Niederlausitzer Grenzwalls, so, wie es die Abbildung 2 von der Weißagker Hochfläche zeigt. Die oberen Meter der Moräne sind meist entkalkt und verlehmt infolge von Bodenbildungsprozessen von der Eem-Warmzeit bis zum Holozän. Die tieferen Bereiche sind unverwittert und für Geschiebeanalysen gut geeignet. Die Abbildung 5 zeigt zusammenfassend die große Verbreitung der S III-Moräne, die hier nur im Bereich jüngerer Erosionsstrukturen fehlt - in den großen Beckenniederungen, in der Aue des Baruther Urstromtals und im Wirkungsfeld der Brandenburger Sander. Es handelt sich also keineswegs, wie EIsSMANN (1997: 46) meint, um eine nur "punktförmig auftretende jüngste Bank (SIII)." Außerdem zeigt die Karte alle 29 bisher bekannten (palynologisch untersuchten) Eem-Vorkommen, und an den mit Doppelkreis gekennzeichneten 6 Standorten sind die Toteishohlformen unter dem Eem mit geschiebeanalytisch bestimmter Grundmoräne vom Typ Saale III ausgekleidet. Die Moräne in solchen
Toteishohlformen zeigt an den Flanken nicht selten gewisse Fließ- und Setzungsstrukturen (seit 1986 gut aufgeschlossen am Punkt 19 in Klinge), stellt aber unverwittert einen echten Till dar, dessen Geschiebespektrum dem der Hochflächen entspricht.

Nach den geologischen Schnitten in CEPEK et al. (1975) sowie zahlreichen Einzelpublikationen verschiedener Autoren ist Geschiebemergel vom Typ S III in ganz Brandenburg anzutreffen, und auch in der mecklenburgischen Küstenregion hat ihn CEPEK nachgewiesen. Für den Niederen Fläming wies ZwIRNER (in CEPEK et al. 1975: 1065) darauf hin, dass S III-Geschiebemergel nur nördlich der Werbig-Petkuser Staffel nachgewiesen werden konnte; das ist dort die äußere Warthe-Randlage. Auf dem Hohen Fläming sah CEPEK (1967) die Fortsetzung in der Schermen-Buckauer Randlage BRUNNERs (1961), jenseits der Elbe schließt sich die Letzlinger Randlage an. Die weitere Fortsetzung führt mit der Göhrde-Staffel südlich an Klötze vorbei nach NW bis zur niedersächsischen Grenze und von dort über die Wierener Berge (südlich Uelzen) nach Westen

Abb. 5: Verbreitung der Saale III-(Warthe 1-)Grundmoräne und limnischer Vorkommen der Eem-Warmzeit. Zusammengestellt von CepeK, Hellwig \& Nowel (1994) auf der Grundlage der Lithofazieskarten Quartär im Maßstab 1:50 000 und zahlreicher Einzelinformationen aus der Erkundungs- und Kartierungstätigkeit.

1 - Grundmoräne Saale III (gSIII) sensu CEPEK; 2 - Maximalausdehnung der Warthe-Kaltzeit ("Lausitzer Phase"); 3 Maximalausdehnung des Brandenburger Stadiums der WeichselKaltzeit; 4 - palynologisch bestimmte Vorkommen der EemWarmzeit; 5 - Eem-Vorkommen über geschiebeanalytisch untersuchtem Saale III-Geschiebemergel; 6 - Braunkohletagebaue; 7 - in Betrieb; 8 - außer Betrieb. Die Nummern der EemVorkommen sind bei CEPEK, HellwIG \& Nowel (1994: 47) erläutert.

Fig. 5: Spreading areas of the Saalian III (= Warthian 1) till and of limnic Eemian deposits.

Compiled by CepeK, Hellwig \& Nowel (1994) on base of the Quaternary Lithofacies Maps scale 1:50 000 and many detailed informations of geological exploring and mapping.

1 - Saalian III till (gSIII) sensu CEPEK; 2 - maximum extent of the Warthian Glaciation ("Lausitz Phase"); 3 - maximum extent of the Brandenburgian Stade of the Weichselian Glaciation; 4 deposits of Eemian Interglacial, palynological indicated; 5 Eemian deposits overlying of Saalian III till which is identificated by till gravel analysis; 6 - lignite opencast mines; 7 - mine in operation; 8 - mine shut-down. Comentary of the Eemian deposit numbers see Cерек, Hellwig \& Nowel (1994: 47). 


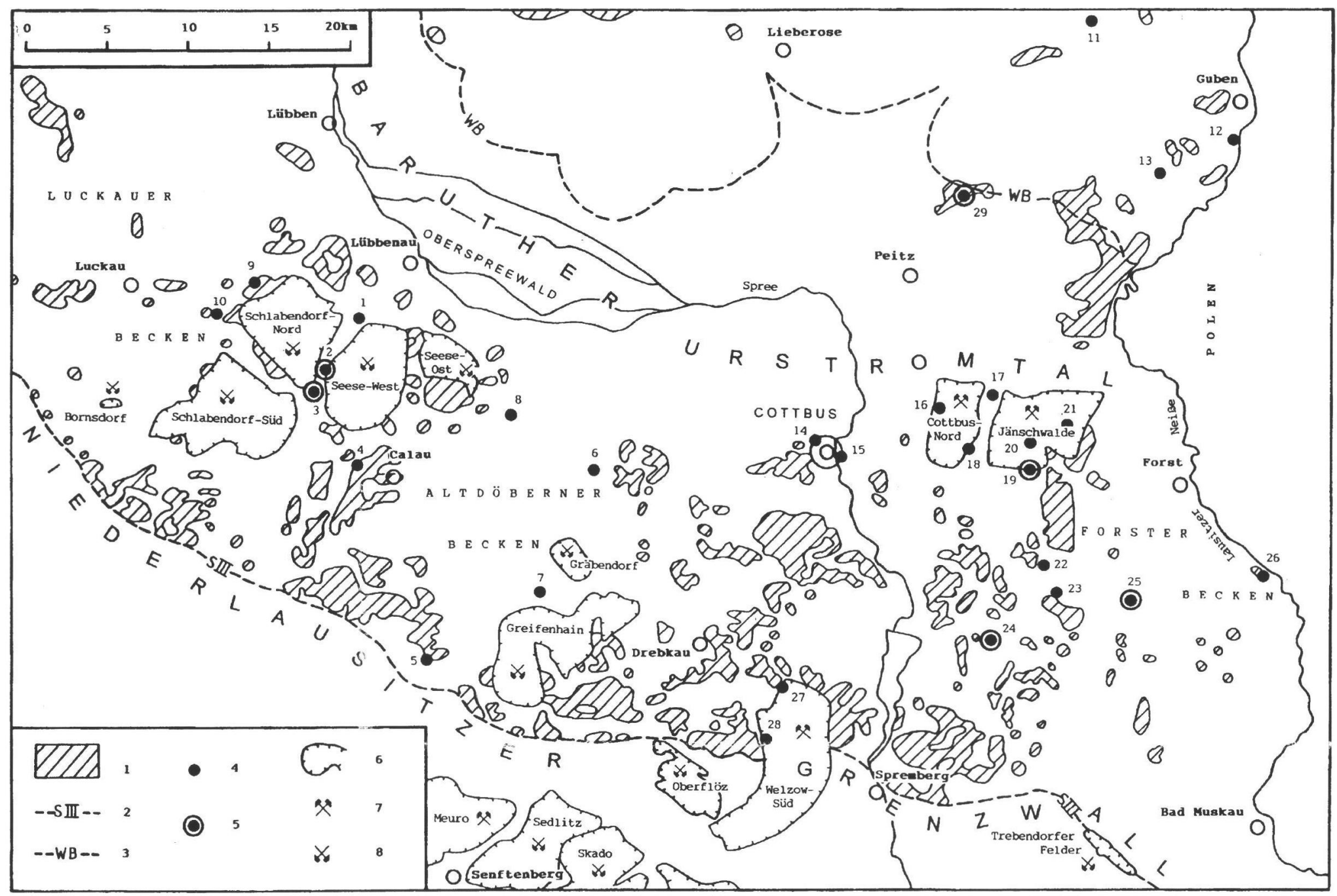


in Richtung auf Soltau zu. Ob die von LANG (1983: 36) bei Fallingbostel, ca. $15 \mathrm{~km}$ südlich Soltau, beschriebene zweite Drenthe-Moräne dem ostbaltischen Saale II-Typ oder möglicherweise dem S III-Typ entspricht, ist zu prüfen. LANG (1993: 26) stellt die Endmoränen im Gebiet des Falken-Berges in "eine späte Phase des Drenthe-Stadiums", sie sind "nachweislich jünger als der Drenthe-Hauptvorstoß." Deshalb sind sie in der Abbildung 1 mit Fragezeichen als Rückzugsstaffel Saale 2 dargestellt.

Bezüglich des weiteren Verlaufs der Maximalausdehnung Warthe 1 gibt es die bereits im Vorwort erwähnten Unterschiede in den Auffassungen der Ämter Niedersachsens und Schleswig-Holsteins sowie Hamburgs. Aufgrund der geschiebeanalytischen Ähnlichkeit der "mittleren Saale-Moräne" Nordwestdeutschlands mit dem ostdeutschen Saale IIITill ist mit Illies (1952), Stephan et al. (1983) sowie Ehlers (1995b: 6) die Fortsetzung der Warthe-Maximalausdehnung in der Lamstedter Phase und auf der Altenwalder Geest südlich Cuxhaven anzunehmen. Sowohl der Niendorf-Till in Hamburg (EHLERs 1992: 101, 1995a: 19) als auch der KudenTill in Schleswig-Holstein "zeichnen sich in typischer Ausbildung durch Flint- und Kreidereichtum aus, unter den Leitgeschieben herrschen süd- bis mittelschwedische Gesteine vor" (SCHLÜTER 1978, in STEPHAN 1995: 6). Eine gleiche Zusammensetzung hat auch der sog. "Drenthe 2-Till" Niedersachsens, alle drei bilden den gleichen stratigraphischen Horizont. Zusammen mit dem ostdeutschen Till vom Typ Saale III stellen sie in Deutschland die Grundmoräne der Glazialfolge Warthe 1 dar (Tab. 1).

\subsection{Glazialfolge Warthe 2}

Über dem Warthe 1 sind in der Tabelle die Tills der nachfolgenden Glazialfolge Warthe 2 angegeben. Der Hennstedt-Till Schleswig-Holsteins, der Fuhlsbüttel-Till Hamburgs und der Vastorf-Till Niedersachsens zeichnen sich durch ein ostbaltisch dominiertes Geschiebespektrum aus. STEPHAN (1995: 6) stellt dazu fest: "Der Hennstedt-Vorstoß (PICARD 1960) brachte erneut Gesteinsschutt aus östlicher Richtung nach Schleswig-Holstein. Dabei wird der baltische Einfluß in mehreren Staffeln von der westlichen Endmoränenkette nach $\mathrm{E}$ hin und gleichzeitig von N/NW nach SE hin zunehmend deutlicher ... . Nordwestlich von Kiel (Bohrungen) kommt zu sehr hohem Gehalt an paläozoischen Kalken auch ein deutlicher bis starker Gehalt an Dolomit hinzu (E-Fazies). Noch auffälliger ist diese östliche Prägung zwischen Mölln und Lauenburg, wo am Segrahner Berg auch roter, toniger Geschiebemergel mit ostbaltischer Zusammensetzung vorkommt (Ehlers 1983 b), die der von Gauger \& MEYER (1970) beschriebenen Vastorfer Fazies aus dem nordöstlichen Niedersachsen entspricht." Aus dem Wendland Niedersachsens erstreckt sich dieser ostbaltisch dominierte und z.T. auch rot gefärbte Till bis in die Altmark hinein in Gestalt des roten Altmärker Geschiebemergels, den schon BERENDT (1886) von Arneburg an der Elbe beschrieben hat. Nach Hucke (1922: 214) "reicht dieser rote Altmärker Geschiebemergel nach Osten über die Elbe bis in die Mark Brandenburg und wurde durch die geologische Landesaufnahme bis in die Kyritzer Gegend verfolgt."

Die äußere Randlage der Warthe 2-Glaziation verläuft in Schleswig-Holstein östlich Husum, Heide und Itzehoe bis zum Nordwesten Hamburgs, dann in Niedersachsen von Lüneburg über die Barendorfer Endmoräne (bei Vastorf in Abb. 1) und nördliche Göhrde-Staffel bis zu den Endmoränen nördlich des altmärkischen Klötze in SachsenAnhalt. Der weitere Verlauf könnte in den Endmoränen der Brunkauer Randlage (КNOTH 1995) südlich und südöstlich Gardelegen sowie in der Doller Randlage der Letzlinger Heide (GLAPA 1971: 1098) zu finden sein, aus deren unmittelbarem Hinterland Glapa (1970: 228) mit Bezugnahme auf GRUNER (1889) roten Altmärker Geschiebemergel über gestauchtem Untergrund beschrieb.

Die Fortsetzung in Brandenburg ist z.Z. noch völlig ungeklärt. Nowel (1996: 62) äußerte die Vermutung, daß dieser Eisvorstoß möglicherweise nicht mehr nach Süden bis in die Niederlausitz hineinreichte. Von polnischer Seite ist allerdings bei RóżYCKI (1972) die Verbreitungsgrenze des zweiten Stadiums der Warta-Vereisung, des Wkra-Stadiums, bis zum Gebiet des Muskauer Faltenbogens angedeutet. Damit wird auf deutscher Seite die Stellung der Jerischker Staffel interessant, die bisher stets als "Rückzugsstaffel der Saale III-Glaziation" interpretiert worden ist (SCHUBERT 1979: 473; Nowel 1984: 12, 1991: 71). Möglichkeiten einer Fortsetzung der "Rückzugsstaffel" deuten sich in 
Gestalt morphologischer Erhebungen und glazigener Lagerungsstörungen im Nordteil der Schlabendorf-Seeser Kohlefelder an, zumal KaUNHOWEN, KeIlHACK \& MeYer (1923) auf dem Blatt Lübbenau auch Endmoränenreste auskartiert hatten. BÖNISCH (1991) sowie BEHRENDT (1998) weisen hier auf oberflächlich verbreiteten Geschiebemergel des Typs SII und offenbar vom CEPEKschen Modell abweichende Lagerungsverhältnisse hin. Ostbaltisch dominierte Proben diskutierte Серек (1991: 44) auch bei der Analyse seines SIIIGeschiebemergels im Liegenden des Schönfelder Eems (2 in Abb. 5). Generell ist zum möglichen Vorhandensein der Glazialfolge Warthe 2 in Brandenburg noch Grundlagenarbeit erforderlich. Insbesondere ist zu klären, ob es sich wie in NWDeutschland zumindest teilweise um einen gesonderten Grundmoränenhorizont handelt oder ob eine direkte Auflagerung von ostbaltischem auf westskandinavischem Till-Material dominiert und deshalb in der Vergangenheit auch nicht als stratigraphisches Phänomen wahrgenommen wurde.

\subsection{Vergleich mit der Gliederung des Saale-Komplexes in Polen}

Die für die Bearbeitung der geologischen Karten im Maßstab 1:50000 als einheitliche Grundlage empfohlene Quartärgliederung Polens (in Mојऽкा 1995c: 126) ermöglicht eine weitgehende Übereinstimmung beim Versuch einer Korrelation in Tabelle 2. Gestützt wird die polnische Gliederung durch zahlreiche Arbeiten aus dem östlichen Mittelpolen (z.B. LINDNER \& GRYZBOWSKI 1982; LINDNER 1984, 1988, 1991 u.a.; LINDNER, WoJTANOWICZ \& BOGUTSKY 1998), aber auch durch CZERWONKA \& KrZYSZKOWSKi (1992a) und andere Beiträge aus dem Bergbaugebiet Bełchatów oder Ber (2000, in Stankowski 2000) aus Nordostpolen. Andere Autoren (z.B. Czerwonka \& KrzYSZKOWSKI 1992b, StanKOWSKi 2000) weisen

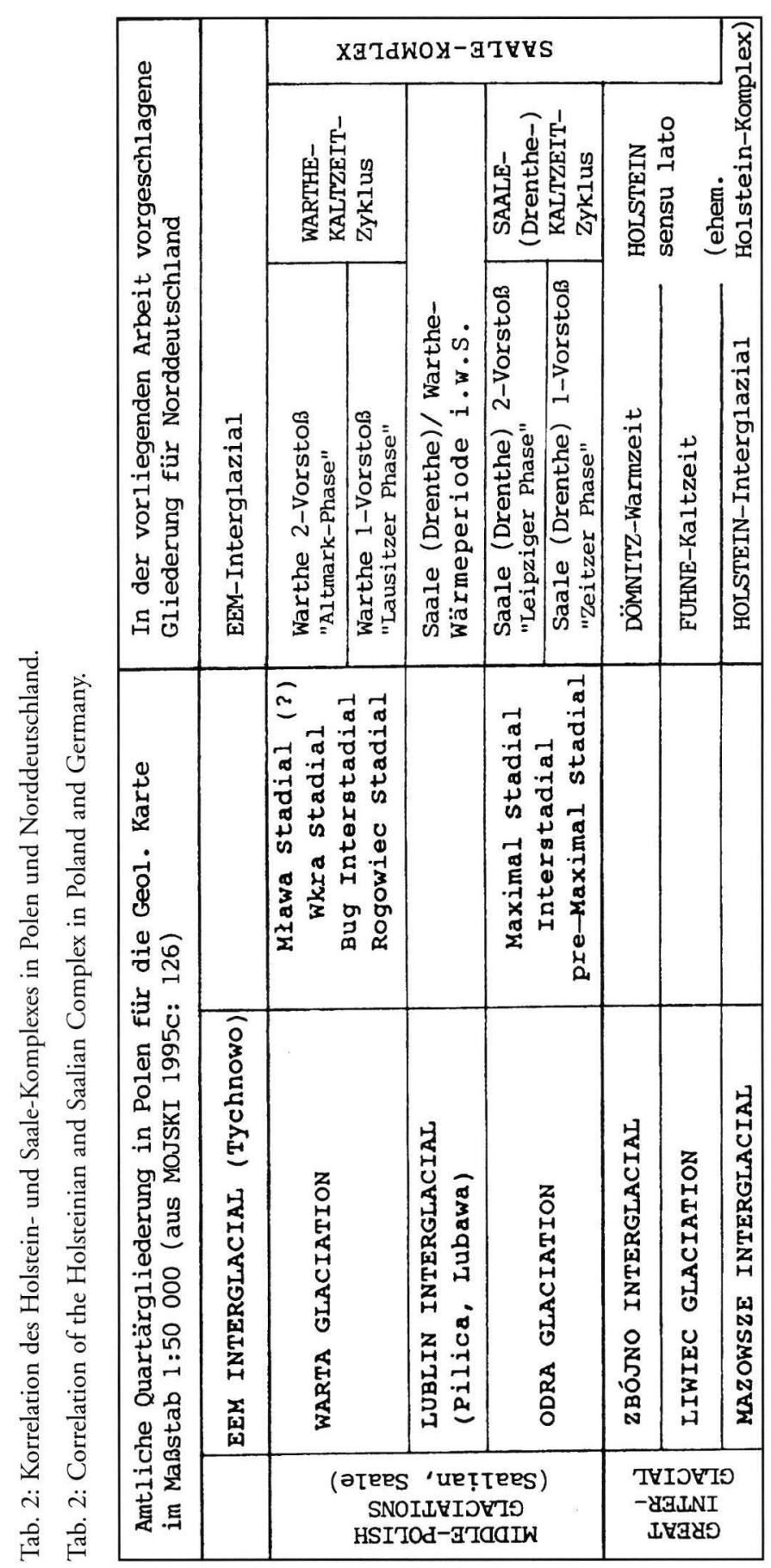


für den Westteil Polens auf eine weniger detaillierte saalezeitliche Schichtenfolge hin. LINDNER et al. (1995) korrelierten die gesamte Quartärfolge Polens zwischen Weißrussland und der Lausitzer Neiße und schlossen dabei an Ergebnisse von CePEK \& Nowel (1991) bei Gosda am Tagebau Jänschwalde an. Bereits Lindner \& GRzYBowski (1982) parallelisierten das Pre-Maximal-Stadial mit der Glazialfolge Saale I, das Maximal-Stadial mit der Glazialfolge Saale II und das Warta mit der Glazialfolge Saale III sensu CEPEK.

Geht man von der in Tabelle 2 vorgenommenen Korrelation aus, dann ergibt sich für den saalezeitlichen Vereisungszyklus eine beachtenswerte Besonderheit: Wie aus dem Namen schon ersichtlich ist, erreichte in Polen erst der zweite Vorstoß die maximale Ausdehnung. MoJSKI (1995c: 125) schreibt dazu: "The first advance reached Central Poland and deposited till in a southward thinning wedge. The subsequent maximum advance of the Odranian ice sheet reached the Sudety Mountains and overrode the Moravian Gate ... ". Das heißt also (um auf die Richtersche Grundkonzeption zurück zu kommen): Der im 1. SaaleEisvorstoß bis zu seinem südlichsten Punkt bei Zeitz in der Leipziger Tieflandsbucht vorrückende westskandinavische Eisstrom verlor weiter östlich im polnischen Gebiet an Energie. Der nach Verlagerung der Eisscheide aus dem finnisch-baltischen Raum vorstoßende ostskandinavisch-baltische Eisstrom erreichte im südpolnischen Gebiet an der Mährischen Pforte seinen südlichsten Punkt und verlor bei der Ausbreitung nach Westen in Deutschland an Energie. In diesem Konsens wäre zu schlussfolgern, dass die Saale-Maximalausdehnung in Polen nicht unserem Saale 1, sondern unserem Saale 2 entspricht und dass es sich bei der SaaleGrundmoräne im Tagebau Berzdorf südlich Görlitz wahrscheinlich bereits um Saale 2 handelt (vgl. Abb. 1). Eine Frage, die einer grundsätzlichen Klärung bedarf und bei deren Beantwortung das Gebiet nördlich Görlitz und beidseitig der Lausitzer Neiße zu einem wichtigen Schnittpunkt werden könnte.

Die Verbreitungsgrenze des Pre-Maximal-Stadials wird von LindNER \& GrZYBOwSKI (1982: 195) sowie Lindner \& Marks (1999: 2) in Gestalt des Krzna-Stadiums im östlichen Mittelpolen, südlich der Flüsse Pilica und Wieprz, ausgewiesen, aller- dings nur etwa bis zum Warthebogen südlich Radomsko. Westlich davon ist die Ausdehnung nicht genau geklärt; nach MoJsKI (1985: 106) gibt es südlich der Kujawy-Pomeranischen Region keine Hinweise auf den Till des Pre-Maximal-Stadials. Aus der Region Wrocław beschreiben CzerwOnKA \& KrzYSZKOWsKi (1992b) sowie KrzYszKOwsKI (1993) nur eine saalezeitliche Grundmoräne, den Smolna-Till, der aufgrund des Geschiebespektrums und ermittelter Eisbewegung aus NE dem Maximal-Stadial zuzuordnen ist. Die wenigen von CzerWONKA \& WITEK (1977) bearbeiteten Bohrungen im nordwestlich anschließenden Raum Żagań-Glogów lassen keine diesbezüglichen Schlussfolgerungen zu. So ist es gegenwärtig nicht möglich, zwischen Radomsko (Mittelpolen) und Niesky (Oberlausitz) eine auch nur annähernde Verbreitungsgrenze der Saale 1-Glaziation anzugeben.

Im Bergbaugebiet von Bełchatów südlich Łódź haben CZERWONKA \& KRZYSZKOWSKI (1992a) eine gründliche Bearbeitung der Till-Stratigraphie durchgeführt. Dem Pre-Maximal-Stadial entspricht hier wohl der T3 (Rokity-Formation), dem Maximal-Stadial der gut untersuchte T 4 (Eawki-Formation). Getrennt durch die warmzeitliche Chojny-Formation, folgen diskordant die warthezeitlichen Tills T 5, T 6 und T 7 (Rogowiec Formation).

Die Geschiebe-Koeffizienten (nach TrembaczowsKI 1961) für den T 4 von Bełchatów, den o.g. Smolna-Till des Raumes Wrocław und den von Czerwonka \& Witek (1977) untersuchten OdraTill im Raum Leszno stimmen überein und beweisen die Anwendbarkeit der Methode. Ein Vergleich mit unseren nach der Methode von CEPEK (TGL 25232, 1971) durchgeführten Kleingeschiebeanalysen ist nicht ohne weiteres möglich, da die verwendeten Komponenten anders gegliedert sind; so zählen z.B. die polnischen Kollegen den Feuerstein zu den Lokalgeschieben, während er bei uns eine wichtige nordische Komponente darstellt. CzerWONKA \& W WTEK (1977) haben anhand weniger Proben beide Methoden angewandt und damit ein Beispiel geschaffen. Dies sollte im Interesse einer besseren stratigraphischen Verständigung anhand von biostratigraphisch sicher positionierten Proben aus dem Grenzbereich beider Staaten von den verantwortlichen Ämtern durchaus weitergeführt wer- 
den, wobei die durch Серек (1979) mitgeteilten Erfahrungen bei der bilateralen Zusammenarbeit hilfreich sein können. Unabhängig davon muss man aber aufgrund der östlicheren Lage des polnischen Staatsgebietes (größere Entfernung zu den Gesteinen Südschwedens und der westlichen Ostsee, größere Nähe zu den baltischen Gesteinen) davon ausgehen, dass eine veränderte Zusammensetzung des Kleingeschiebespektrums zu erwarten ist. Die in der vorliegenden Arbeit als Voraussetzung für Korrelationen zwischen Südbrandenburg und Schleswig-Holstein zugrunde gelegte annähernde Gleichheit der Kleingeschiebespektren kann weiter östlich nicht uneingeschränkt gelten.

\subsection{Zusammenfassung zu den saale- und warthezeitlichen Glazialfolgen und Vereisungszyklen}

In der Abbildung 6 ist der Vorschlag zur Deutung des saale-(drenthe-)zeitlichen und des warthezeitlichen Vereisungszyklus für das Gebiet zwischen Schleswig-Holstein und der Niederlausitz sowie Westsachsen zusammengefasst dargestellt. Daraus ergeben sich folgende Schlussfolgerungen und Empfehlungen:

1. Die Glazialfolge Saale 1 (oder Drenthe 1) resultiert aus einem westskandinavischen Eisstrom und markiert in Deutschland die Maximalausdehnung der Saale-Vereisung, auch als Saale-Hauptvorstoß, Haupt-Drenthe oder Saale-Kaltzeit sensu stricto bezeichnet. Der EIssmannsche Begriff "Zeitzer Phase" oder Zeitzer Vorstoß steht als Synonym und kann (zumindest in Ostdeutschland) über den sächsischen Raum hinaus angewendet werden. Die Saale 1-Grundmoräne ist ein schwedisch dominierten Till vom Typ SI sensu Cерек. In Polen wird der erste Saale-(Odra-)Vorstoß als Pre-MaximalStadial bezeichnet; er erreichte hier nicht die weiteste Ausdehnung.

Die Glazialfolge Saale 2 (oder Drenthe 2) resultiert aus einem ostbaltischen Eisstrom. Ihre maximale Ausdehnung verläuft aus der südlichen und westlichen Niederlausitz zur westelbischen Tauchaer, Petersberger und Calvörder Randlage und dann wahrscheinlich im Zuge der Rehburger Phase nach Westen. Die Saale 2-Grundmoräne in diesem Ver- ständnis ist ein ostbaltisch dominierter Till, der in Ostdeutschland dem Typ SII sensu Cерек entspricht oder nahe kommt, in NW-Deutschland durch die Rote Drenthe-Moräne repräsentiert wird. Der Eissmannsche Begriff "Leipziger Phase" oder Leipziger Vorstoß steht als Synonym und kann (zumindest in Ostdeutschland) über den sächsischen Raum hinaus angewendet werden. In Polen wird der zweite Saale-(Odra-)Vorstoß als MaximalStadial bezeichnet; er erreichte die Maximalausdehnung der Odra-Kaltzeit an der Mährischen Pforte und führte zur Ablagerung des weit verbreiteten Odra-Tills sensu stricto.

„Zeitzer Phase" und „Leipziger Phase“ bilden gemeinsam den saalezeitlichen Vereisungszyklus. Sie sind als eigenständige, aus der Verlagerung der Eisscheide resultierende großräumige Eisvorstöße zu definieren, zwischen denen allerdings kein Spielraum für eine warmzeitliche Entwicklung eingeräumt werden kann.

2. Die Glazialfolge Warthe 1 resultiert aus einem erneuten westskandinavischen Eisstrom und markiert in Deutschland das Maximum der Warthevereisung, das in seiner Ausdehnung im Wesentlichen mit dem Warthe-Stadium im Sinne von Woldstedt $(1927,28)$ identisch ist. Die Warthe 1-Grundmoräne ist ein schwedisch dominierter Till vom Typ S III sensu CepeK, in Hamburg und Schleswig-Holstein als Niendorfbzw. Kuden-Till bezeichnet, in Niedersachsen allerdings abweichend als "Drenthe 2-Till" interpretiert. In Anlehnung an CePEKs Lausitz-Kaltzeit wird als Synonym in Ostdeutschland der Begriff "Lausitzer Phase" vorgeschlagen. In Polen wird der erste Warthe-(Warta-)Vorstoß, dessen Endmoränen die Fortsetzung des Niederlausitzer Grenzwalls östlich der Lausitzer Neiße bilden, als RogowiecStadial bezeichnet.

Die Glazialfolge Warthe 2 resultiert wiederum aus einem ostbaltischen Eisstrom, der in SchleswigHolstein als Hennstedt-Vorstoß bekannt ist. Die wiederum ostbaltisch dominierte Warthe 2-Grundmoräne wird in Schleswig-Holstein durch den Hennstedt-Till, in Hamburg durch den FuhlsbüttelTill und in Niedersachsen durch den Vastorf-Till (den man hier als einzigen Warthe-Till betrachtet) repräsentiert. In Ostdeutschland sind ihr Teile des S II-Tills sensu CEPEK zuzurechnen, zu denen sicher 


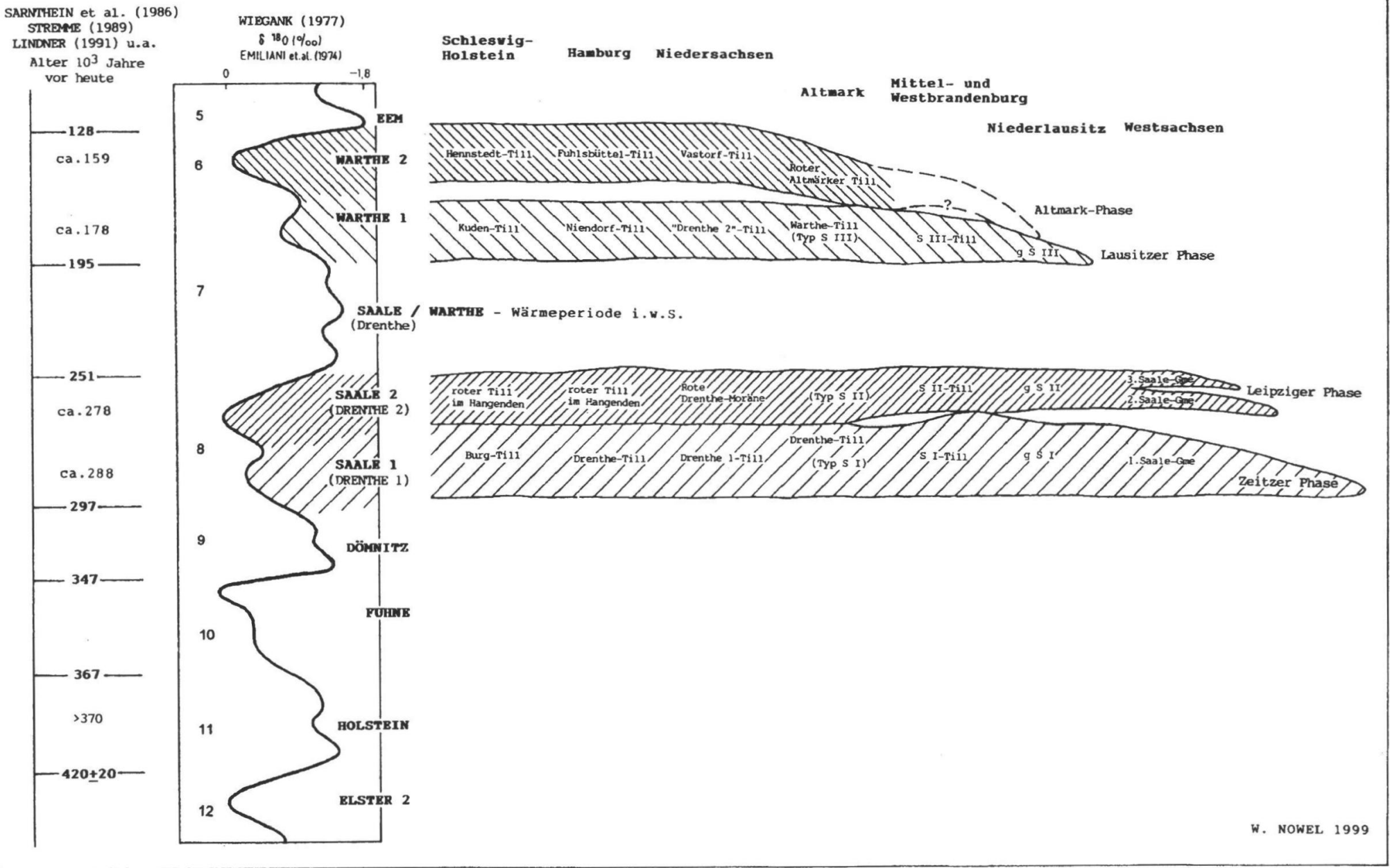


der in Sachsen-Anhalt und Nordwestbrandenburg verbreitete rote Altmärker Geschiebemergel gehört. Deshalb wird hier als Synonym der Begriff "Altmark-Phase" empfohlen. In Mittelbrandenburg und der Niederlausitz ist die Verbreitung noch völlig ungeklärt. In Polen wird der zweite Warthe(Warta-)Vorstoß als Wkra-Stadial bezeichnet.

"Lausitzer Phase" und "Altmark-Phase" bilden gemeinsam den warthezeitlichen Vereisungszyklus. Sie sind ebenfalls als eigenständige, aus der Verlagerung der Eisscheide resultierende großräumige Eisvorstöße zu definieren, zwischen denen kein Spielraum für eine warmzeitliche Entwicklung eingeräumt werden kann.

3. Die Zuordnung der Glazialfolgen des saale- und des warthezeitlichen Vereisungszyklus zu den ${ }^{18} \mathrm{O}$ Stufen der ozeanischen Gliederung in der Mitte der Abbildung 6 basiert auf einer Darstellung in WieganK (1977: 710), der damals bereits die CEPEKschen Glazialfolgen SI und SII mit der Stufe 8 und die Cepersche Glazialfolge SIII mit der Stufe 6 korreliert hat. Kurvenverlauf und Zuordnung sind mit moderneren Darstellungen wie BASSINOT et al. (1994, in BRONGER 1999: 38) im Prinzip konsensfähig. Die Setzungskurve nach Thоме (1998: 41) ist dabei nicht berücksichtigt.

Das Eem-Interglazial besetzt nach übereinstimmender Auffassung die Stufe 5, Teilstufe 5 e. Zum Holstein-Interglazial differieren die Zuordnungen zwischen Stufe 7 (Linke et al. 1985), Stufe 9 (ZAGWijn 1992) und Stufe 11 (Sarntheim et al. 1986, BAsSINOT et al. 1994); CEPEK hielt 1981 in der TGL 25 234/07 sogar die Stufe 13 für möglich. Mit Bezugnahme auf die überregionalen Korrelationen

Abb. 6: Korrelation der Saale (Drenthe)- und WartheTills zwischen Schleswig-Holstein, Westsachsen und der Niederlausitz und Versuch einer Zuordnung zu den ${ }^{18} \mathrm{O}$ Stufen der ozeanischen Gliederung sowie den Daten der absoluten Altersgliederung BP.

Darstellung unmaßstäblich und stark überhöht.

Fig. 6.: Correlation of Saalian (Drenthian) and Warthian tills by Schleswig-Holstein, Westsachsen and the Niederlausitz and associate attempt with the ${ }^{18} \mathrm{O}$ stages of the deep sea division as well as the absolute age BP.

Presantation non-uniform scale division. von Bronger (1999) und die im Folgenden diskutierten Altersdaten behält der Autor die WIEGaNksche Zuordnung des Holstein sensu stricto zur Stufe 11, der Fuhne-Kaltzeit zur Stufe 10 und der Dömnitz-Warmzeit zur Stufe 9 bei. Die Stufe 7 bleibt in dieser Konstellation für eine Saale (Drenthe)/Warthe-"Wärmeperiode" frei, die in Russland mit dem Odintsovo-Interglazial und in Polen mit der Lubawa- oder Grabówka-Wärmezeit belegt ist, in Deutschland aber noch einer weiteren sachlichen Diskussion bedarf (dazu Abschn. 5).

Zur Untergrenze des Eem-Interglazials bei $128 \mathrm{ka}$ $\mathrm{BP}$ gibt es eine weitgehende Übereinstimmung der Auffassungen. Als Beispiele aus dem mitteldeutschen Periglazialgebiet seien die Eem-Travertine von Burgtonna und Taubach in Thüringen genannt mit U/Th-Daten von 93-109 ka BP bzw. 111-116 ka BP (Mania 1997: 55, 99), als Beispiele aus der Lausitzer Region der Untere Ton des Eem von Klinge (19 in Abb. 5) mit korrigiertem TL-Alter von $115 \pm 18 \mathrm{ka}$ BP und zwei Proben aus dem Eem von Schönfeld (2 in Abb. 5) mit korrigiertem TL-Alter von $107 \pm 20 \mathrm{ka}$ BP bzw. $129 \pm 21 \mathrm{ka} \mathrm{BP}$ (КRbetschek in Eissmann \& LitT 1994: 295).

Für die Einordnung des Holstein-Interglazials in die ${ }^{18} \mathrm{O}-S t u f e 11$ sind die Untersuchungen am Profil Wacken nordwestlich Hamburg von maßgeblicher Bedeutung, wo die U/Th-Datierung mariner Molluskenschalen ein Alter von $>350$ und $>370$ ka BP ergab (SARntheim et al. 1986, siehe auch Stremme 1989: 193 sowie Bronger \& Heinkele 1989: 180). Letztgenannte Autoren verweisen außerdem auf ein Alter von 300-350 ka BP für stratigraphisch der Dömnitz-Warmzeit ( $\left.{ }^{18} \mathrm{O}-\mathrm{Stufe} 9\right)$ entsprechende marine Muschelschalen vom Profil Herzeele (Nordfrankreich) sowie auf das von FuHrmanN (1983) bestimmte $40 \mathrm{Ar} / 39 \mathrm{Ar}$-Alter von $420 \pm 20 \mathrm{ka}$ BP für den zur Elster-Kaltzeit überleitenden Selbergit-Tuff vom Mittelrheingebiet. In dem floristisch und faunistisch zum Holstein-Komplex gehörenden, außerordentlich gründlich bearbeiteten Profil Bilzingsleben II in Thüringen ergaben U/Th- und ESR-Datierungen durch SCHWARCZ et al.(1988) für den Travertin mit der Homo erectus-Fundschicht ein Alter zwischen ca. 320 und $420 \mathrm{ka}$ BP (MANia 1997: 17). Aus den Basispartien des Mazovian (= Holstein s.str.) von Krepiec in Polen nennen Lindner \& MarCINIAK (1998: 249) ein TL-Alter von $400 \mathrm{ka}$, aus 
überlagernden Sanden der Liwiec (= Fuhne)-Kaltzeit von $350 \mathrm{ka}$ und aus darüber folgenden Sedimenten der Zbójno (= Dömnitz)-Warmzeit von 334 ka BP. NityCHOruK et al. (1999: 25) stellen für das unmittelbare Liegende des Mazovian von Wilczyn ein TL-Alter von $396 \pm 59$ ka BP dar. Für den Saale-Komplex teilen die genannten Autoren und darüber hinaus unter anderem KRUPIŃSKI, Marks \& Szynkiewicz (1987) sowie Mojski (1995a, b) aus dem polnischen Gebiet ein umfangreiches Datenmaterial von TL-Altersbestimmungen mit. Es bildet die Grundlage für die Einordnung der saalezeitlichen Glazialfolgen in die ${ }^{18} \mathrm{O}$-Stufe 8 und der warthezeitlichen Glazialfolgen in die Stufe 6. Stremme (1989: 193) gibt auf der Grundlage von TL-Datierungen durch Zöller für drenthezeitliche Sande im Hangenden des Profils Wacken ein Alter von $269 \pm 22 \mathrm{ka} \mathrm{BP}$ an. Aus Messungen im rheinischen Lössgebiet verallgemeinert er für die Warthezeit 130-190 ka BP und für die Drenthezeit 220-300 ka BP.

Übereinstimmend mit TL-Altern des russischen Odintsovo-Interglazials (in LindNER \& GRZYBOwsKI 1982: Fig. 4) teilen KRUPIŃSKI \& MARKS (1986) sowie KrupińsKi, Marks \& SzYNKIEWICZ (1987) TL-Daten zur polnischen Lubawa- oder GrabówkaWärmezeit von Losy und Bełchatów mit, die eine Einstufung in die ${ }^{18} \mathrm{O}$-Stufe 7 rechtfertigen. Das gilt auch für Altersdaten aus folgenden ostdeutschen Intrasaale-Profilen: Für den Unteren Travertin von Ehringsdorf (Thüringen) ergaben U/Th- und ESRDatierungen durch SCHWARCZ et al. (in MANIA 1997: 45) ein Alter um 200 ka BP, JäGER (1999) teilte dazu neue Ergebnisse von 254-257 ka BP mit. Der Travertin IV von Bilzingsleben hat nach 234U/230Th-Mikroproben-Datierungen von MALLIK ein Alter von etwa 220000 Jahren (Mania \& Altermann 2001: 129). Für das Optimum des Interglazials von Neumark-Nord (Geiseltal) ermittelten Zöller \& Karelin (in Mania 1997: 45) ein TL-Alter von 180-210 ka BP. Für eine Schluffschicht im Tranitzer Fluviatil des Tagebaus Jänschwalde (4a in Abb. 1) bestimmte KRneTsCHeK (in EISSMANN \& LitT 1994: 295) ein TL-Alter von $201 \pm 27$ ka BP (korrigiertes Alter 247+43-39 ka BP).

4. Mit den von Eissmann \& LitT (1994: 293/94) sowie Eissmann (1998) publizierten, generell jünger ausfallende Daten aus Westsachsen sind die vorstehend genannten allerdings nicht vereinbar. Diesbezüglich ist eine Überprüfung erforderlich. Dabei wäre es sinnvoll, bei weiteren Datierungen auch saale- und warthezeitliche Sedimente aus Profilen des Niederlausitzer Braunkohlereviers in die Untersuchungen einzubeziehen. Die bei EIssmanN genannten Daten (z.B. 150 ka BP für den 1. SaaleVorstoß) stützen sein seit langem vertretenes, von der hier diskutierten Modellvorstellung (Abb. 6) grundsätzlich abweichendes Gliederungsschema einer monoglazialen Entwicklung von Drenthe bis einschließlich Warthe und seine Zuordnung beider stratigraphischen Kategorien in die ${ }^{18} \mathrm{O}$-Stufe 6 . Er engt damit das gesamte Vereisungsgeschehen der Saale-(Drenthe-) und Warthezeit auf einen Zeitraum von nicht einmal $25 \mathrm{ka}$ ein.

Als geologisches Hauptargument für eine solche Zuordnung betrachtet EIsSMANN (1990, 1994 u.a.) die direkte Auflagerung der als Eem interpretierten Interglaziale von Gröbern, Grabschütz und Neumark-Nord auf Drenthe-Grundmoräne der Zeitzer oder Leipziger Phase. Diese Argumente sind aber nicht unumstritten: In den Interglazialablagerungen von Neumark-Nord und Grabschütz weisen neben der o.g. TL-Datierung mehrere floristische und faunistische Besonderheiten auf ein höheres Alter als Eem hin (dazu Abschn. 5). Das Interglazial von Gröbern ist ein sicheres, floristisch und faunistisch mit dem Profil von Schönfeld (R. \& U. Striegler 1991) korrelierbares Eem, die postulierte Genese des Beckens als saale-(drenthe-)zeitliche Toteishohlform ist aber nicht zwingend. Auch eine jüngere erosive Entstehung und periglaziale Ausgestaltung nur $60 \mathrm{~km}$ vor dem Warthe-Außenrand ist denkbar; die palynologisch dokumentierte Sedimentation beginnt erst im Spätwarthe. Solche Erosionsstrukturen, in denen Eem erosionsdiskordant auf Drenthe oder sogar älteren Schichten lagert, sind auch aus der Niederlausitz bekannt.

Als zweites Argument gegen eine Intrasaale-Warmzeit und damit den eigenständigen Charakter des drenthe- und warthezeitlichen Vereisungszyklus wird auch das Fehlen entsprechender Terrassen angesehen. "Dabei sollte jedoch bedacht werden, daß zumindest ein Teil unserer Terrassen hinsichtlich der stratigraphischen Stellung einen relativ großen Spielraum zulässt" (WoLf 1992: 189). Es sei auch gestattet, daran zu erinnern, dass am Nieder- 
rhein seit Quitzow (1956) die Krefelder Mittelterrasse (Untere Mittelterrasse 4) dem Warthe-Stadium zugeordnet wird (WOLDSTEDT 1962: 119; KLOSTERMANN 1995: 60, 74). In Thüringen erbringt MaNiA (1997: 37) den Nachweis für eine warthekaltzeitliche "untere Stufe der Mittelterrasse", und stellt fest: "Eine weitere Schlußfolgerung aus den jahrelangen Untersuchungen bei Bilzingsleben ist die Erkenntnis, daß der klimatisch gesteuerte ErosionsAkkumulationsprozeß in den Flußtälern des Mittelgebirgsvorlandes viel komplizierter ist, als es herkömmliche terrassenmorphologische Untersuchungen erkennen lassen."

Eissmann (1990: 42) räumte ein: "Die Widersprüche sind wohl selbst auf lange Sicht nicht lösbar, da die den Gliederungen zugrunde liegenden Befunde oft weder subjektiv noch objektiv überprüfbar sind und die Befundinterpretation ... dem individuellen Ermessen einen breiten Spielraum läßt ... Durch Kompromisse in der Interpretation allein sind die heutigen Widersprüche in der europäischen Quartärstratigraphie nicht zu überwinden, sondern nur durch ein zähes, intensives Weiterforschen mit verschiedenen Methoden und ein gewissenhaftes Bewerten der Befunde."

\section{Zum Problem der Wärmeperiode zwischen Drenthe und Warthe}

\subsection{Analyse des gegenwärtigen Kenntnisstandes}

Eine Hauptursache der eben zitierten Widersprüche ist zweifellos die bis heute nicht eindeutig geklärte Frage nach der Existenz einer Wärmeperiode zwischen Saale i.e.S. oder Drenthe und Warthe; hier stehen sich in Deutschland gegensätzliche Positionen hartnäckig gegenüber. Der Nachweis von MenKe (1985: 73), dass die Typuslokalität der von PiCard (1959) begründeten Treene-Warmzeit bei Husum "höchstwahrscheinlich ein Pseudonym der Eem-Warmzeit" darstellt, brachte zwar das Aus für den Terminus "Treene", nicht aber ein Ende der Diskussion um das Gesamtproblem.

Wer "Drenthe" und "Warthe" im WoldstedTschen Sinne als Stadien anerkennt - und das haben im von BeNDA (1995) anlässlich des Berliner
INQUA-Kongresses herausgegebenen "Quartär Deutschlands" fast alle Autoren der norddeutschen Länder getan - , der muss zwangsläufig zwischen beiden auch die gleichrangige klimastratigraphische Kategorie "Interstadial" akzeptieren. Das haben auch LitT \& Turner (1993: 127) nicht ausgeschlossen.

Demnach geht es, genau genommen, bei der Mehrheit der Autoren nicht um die Beantwortung der Frage "Wärmeperiode ja oder nein?", sondern um eine stichhaltige Beweisführung bezüglich des klimastratigraphischen Ranges einer solchen wärmeren Periode zwischen dem saale-(drenthe-) zeitlichen und dem warthezeitlichen Vereisungszyklus. Hierzu gibt es noch einen großen Klärungsbedarf, jedoch ist entsprechend dem Kenntnisstand von Region zu Region eine differenzierte Einschätzung erforderlich. Dabei sollte man stets auch die Mahnung von KRASNOV (1978: 72) beherzigen: "Wenn ein Schichtglied im stratigraphischen Profil einer Region fehlt, darf dies nicht von vornherein zum Ausschluß dieser Schichten führen, wenn die gleichen Horizonte auf dem Territorium eines anderen Bezirkes bestimmt werden konnten."

"Russia is a key area for the Saalian stratigraphy. Two till sheets are correlated with the Saalian (Complex, W. N.) of western Europe: the Dnjepr Till and the Moscow Till. The glaciations which deposited these tills are separated from each other by the Odintsovo deposits, which are interpreted as either of interglacial or interstadial charakter" (Ehlers, Kozarski \& Gibbard 1995: 550). Die voll-interglaziale Entwicklung der Odintsovo-Warmzeit ist seit der Arbeit von Moskwitin (1960) eigentlich nicht zu bestreiten, sofern man vollständig erhaltene Profile betrachtet. In dem von Goretsky, Chebotareva \& Shick (1982) anlässlich des Moskauer INQUA-Kongresses herausgegebenen Sammelband sind mehrere Profile mit Pollenspektren beschrieben sowie geologische Schnitte dargestellt, in denen das Odintsovo-Interglazial von Geschiebemergel der Dnjepr-Kaltzeit (= Saale s.str. bzw. Drenthe) unterlagert und von zwei Geschiebemergeln der Moskau-Kaltzeit (= Warthe) überlagert wird. Zwei hochinterglazial ausgebildete Klimaoptima (Glasowski-Optimum und Roslavlski-Optimum) werden im Pollenspektrum von einer kühleren Phase getrennt, was MosкwiтाN (1960) 
zur Bezeichnung „kühleres Interglazial" veranlasste. In Belorussland wird ein Interglazial im gleichen stratigraphischen Niveau als Shklov bezeichnet, in Litauen als Snaigupele. Im Snaigupele-Interglazial, das ERD (1987) eingehend mit der Uecker-Warmzeit von Röpersdorf verglich, ist keine kühlere Phase zu beobachten, jedoch eine zweimalige Kulmination von Quercus. Gewisse Probleme bei der palynologischen Korrelation zwischen Odintsovo, Shklov und Snaigupele, auf die ERD (1987: 309) ebenfalls eingeht, müssen noch gelöst werden. Sie ändern aber nichts an der Tatsache, dass in Osteuropa vom westlichen Baltikum bis zur Russischen Tiefebene voll entwickelte Interglazialprofile zwischen Dnjepr- und Moskau-Vereisung nachgewiesen sind. Auch der Umstand, dass einige ehemals als Odintsovo oder Shklov gedeutete Vorkommen inzwischen in den Cromer-Komplex gestellt werden mussten, beeinflusst diese Feststellung nicht.

Bei den unter 4.6 und 4.7 aus Ost- und Mittelpolen bereits erwähnten Profilen, die auf eine Wärmeperiode zwischen Odra- und Warta-Vereisung hindeuten, handelt es sich sowohl um limnisch-fluviatile organogene Ablagerungen aus dem warthezeitlichen Vereisungsgebiet als auch um Paläoböden aus den periglazialen Lößgebieten in Malopolska und dem Lubliner Hochland. Ihre stratigraphische Stellung ist durch die geologischen Lagerungsverhältnisse und durch TL-Datierungen gestützt, der klimastratigraphische Rang (interglazial oder interstadial) ist nicht immer eindeutig definiert. So gibt es verschiedene Lokalbezeichnungen, die alle den gleichen stratigraphischen Abschnitt meinen: Lublin-Interglazial, Pilica-Interstadial, GrabówkaInterglazial, Lubawa-Interglazial. Auf drei bedeutsame Profile sei im Folgenden etwas näher eingegangen.

Das Lubawa-Interglazial wurde von KRUPIŃSKI \& Marks (1986) im Profil Losy bei Lubawa im westlichen Masurischen Seengebiet begründet. Hier konnte ein komplettes voll-interglaziales Pollenspektrum mit $65 \%$ Quercus im Wärmeoptimum nachgewiesen werden. Das Vorhandensein von Azolla filiculoides sowie das Auftreten des TiliaGipfels vor dem von Corylus sprechen gegen eine Zuordnung zum Eem, sondern stellen eher Parallelen zur Snaigupele- und zur Uecker-Warmzeit dar. TL-Datierungen der unterlagernden Sande bei 273 ka BP und hangender Sande bei 230 ka BP stützen die stratigraphische Einordnung zwischen Odra und Warta in die ${ }^{18} \mathrm{O}$-Stufe 7.

Das Grabówka-Interglazial vom gleichnamigen Ort am Unterlauf der Weichsel wurde durch MaKowsKA (1977) publiziert, ein geologischer Schnitt ist auch bei Lindner (1984: 38) abgebildet. Die limnischen Sedimente werden hier von MazovianFluviatil und Odra-Till unter- und von Warta-Till und Eem überlagert. Ein vollständiges Pollenspektrum wurde leider nicht untersucht, einzelne Pollenproben brachten aber den Nachweis von Corylus, Tilia, Abies, Ulmus und maximal $22 \%$ Quercus, woraus die genannten Autoren die Möglichkeit einer voll-interglazialen Entwicklung ableiten. MojSKI (1995a: 216) weist auf die Unvollständigkeit der palynologischen Beweisführung hin und regt Nacherkundungsbohrungen zur eindeutigen Klärung an.

Sehr eingehend von mehreren Autoren untersucht ist die Chojny-Serie im Tagebau Bełchatów, deren Klimaoptimum von KRUPIŃSKI, MARKS \& SZYNKIEwICZ (1987) ebenfalls als Grabówka-Interglazial gedeutet wird. Die Chojny-Serie ist eine mit unserem Tranitzer Fluviatil faziell-genetisch vergleichbare Abfolge fluviatiler Kiese und Sande, die in ehemaligen Altwasserbildungen Reste organogener Sedimente (Schluff, Mudden, Torf) enthält. Die Serie wird, wie unter 4.6 bereits dargelegt, von Odra-Till (Ławki-Formation) unter- und von Warta-Till (Rogowiec-Formation) überlagert. Die stratigraphische Position zwischen Odra und Warta ist unbestritten und wird durch mehrere TLDatierungen zwischen $264 \mathrm{ka} \mathrm{BP}$ (Basissande) und $183 \mathrm{ka} \mathrm{BP}$ (Hangendsande) gestützt ( $={ }^{18} \mathrm{O}$-Stufe 7$)$. Untersuchungen und Entscheidungen zum klimastratigraphischen Rang gestalten sich schwierig, da in der fluviatilen Fazies die organogenen Schichten oft syngenetisch durch Erosion wieder reduziert werden. In den palynologisch bearbeiteten Profilen 1/1985 und 2/1985 konnten KRUPIŃSKI, Marks \& SZYNKIEWICZ (1987) nur subarktische bis maximal boreale Verhältnisse nachweisen. Im Profil 3/1986 gelang aber anhand von 60 lückenlos aneinander gereihten Proben die Erarbeitung eines vollständigen Pollendiagramms von Tundra über borealen Kiefern-Birken-Wald zu ausgeprägtem Eichenmischwald (im oberen Teil mit starker Tannen- und Fichtenverbreitung) und als Abschluss wieder borealem Kiefern-Birken-Fichten-Wald unter einer flu- 
viatilen Erosionsdiskordanz. Vom Lubawa-Interglazial unterscheidet sich das Pollenspektrum unter anderem durch ein geringeres Quercus-Optimum (knapp $15 \%$ ) und durch ein gleichzeitiges Dominieren von Tilia und Corylus. Aber: "Elements of deciduous forest reach $40 \%$ in their main phase and hence speak for the interglacial type of the flora" (KRUPIŃSKI, MARKS \& SZYNKIEWICZ 1987: 373). Bei der INQUA-SEQS-Tagung in Lódź 1994 fand dieses Ergebnis allerdings keine Mehrheit; man folgte der Auffassung von JASTRZEBSKA-MAMELKA (1993 in MojSKI 1995a: 216): "...this is an interstadial unit with a specific floristic picture, and it is much warmer than the other numerous interstadial units in the Pleistocene of Poland." Nun: $\mathrm{Ob}$ "kühleres Interglazial" (wie MosKwITIN formulierte) oder "warmes Interstadial" - eine ganz ausgeprägte Wärmeperiode zwischen Odra- und Warta-Vereisung ist in Mittelpolen zweifelsfrei nachgewiesen. Aus dem Westteil Polens fehlen bisher Hinweise auf eine solche Warmzeit. CzerwonKa \& KRZYSZKOWSKI (1992b) legen im Raum Wrocław den Sedimentationsbeginn der fluviatilen Oderschotter (Odra River Formation) in den Zeitraum zwischen Odra und Warta, den sie hier als Pilica-Interstadial bezeichnen.

Das Tranitzer Fluviatil, im östlichen Niederlausitzer Braunkohlerevier zwischen Cottbus-Forst und Weißwasser-Drachhausen verbreitet, wurde durch Hellwig (1975) begründet und eingehend beschrieben; die spezielle Situation im Tagebau Jänschwalde ( 4 in Abb. 1) ist einschließlich von Hellwig durchgeführter Geröllanalysen bei Hellwig, KüHner \& Nowel (1994: 160, 164-166) erläutert. Nach der unter 2. geführten Argumentation kann die stratigraphische Stellung zwischen den Glazialfolgen Saale 2 und Warthe 1 als sicher gelten. Der überwiegend sandige Untere Teil des Fluviatilkörpers wird wegen seiner Geröllzusammensetzung (reichlicher Anteil an nordischen Komponenten, nach oben abnehmend) und dem palynologischen Nachweis arktischer bis subarktischer Klimaverhältnisse in eingelagerten Mudden (ERD und SEIFERT in Hellwig 1975) dem Saale 2-Kataglazial zugeordnet. An seiner Obergrenze im Profil des Ostrandschlauches Jänschwalde gefundene kleine Windkanter belegen eine ehemalige Landoberfläche; aus dem gleichen Niveau bei Klinge stellte
HeLlWIG (1992) mehrere Fundstücke vor, die er als nicht abgerollte Steinartefakte deutet. Der insgesamt stärker kiesführende Obere Teil des Fluviatilkörpers enthält in der Fraktion 4-10 mm fast nur südliche Geröllkomponenten mit 57-78\% Quarz und 9-15\% Feldspat aus dem Isergebirge, die ihn als Ablagerung des Flusssystems der Lausitzer Neiße kennzeichnen. Ein 2-4 m mächtiger Kieshorizont im Basisbereich wurde durch Schotteranalysen (Hellwig 1975; Hellwig, Kühner \& Nowel 1994) und Schwermineralanalysen (THIEKE 1975) als Ausmerzungszone instabiler Komponenten identifiziert, die als Wirkung eines warmzeitlichen Klimas gedeutet wird. Dieser Bereich wird als Klimaoptimum während der Bildungszeit des Tranitzer Fluviatils interpretiert, darüber folgt der Warthe 1-Anaglazialabschnitt.

Diese Interpretation wird gestützt durch den palynologischen Nachweis wärmerer Klimaverhältnisse in Schluffmudde- und Torfmuddelagen aus dem Kieshorizont; ein interglaziales Pollenspektrum konnte allerdings bisher nicht nachgewiesen werden. Die vollständigen Zählergebnisse der in den $70 \mathrm{er}$ und $80 \mathrm{er}$ Jahren durchgeführten Untersuchungen teilt ERD (1994a) mit und kommt zu dem Schluss: "Wahrscheinlich ging die Entwicklung von arktischen zu borealen (kühlgemäßigten) Klimabedingungen ... Die thermophilen Elemente (insbesondere Corylus, Quercus und Carpinus) in der oberen Bank könnten ... höchstens subboreales Klima im Übergangsfeld zwischen kühlgemäßigtem und vollinterglazialem gemäßigtem Klima bezeugen. Derartige Verhältnisse können aber auch noch in den Optima von Interstadialen zu verzeichnen sein." Als Hinweis auf das ursprüngliche Vorhandensein und nur durch Erosion in der fluviatilen Fazies bedingte Fehlen der vollinterglazialen EMWPhase kann möglicherweise ein im betreffenden Kieshorizont an der südlichen Tagebauböschung (östl. 4a in Abb. 1) gefundener, ca. $7 \mathrm{~m}$ langer Baumstamm gelten, der vom Labor für quartäre Hölzer Adliswil (SсHосн 1993) als Quercus sp. bestimmt wurde. Auf die wahrscheinliche Identität des Tranitzer Fluviatils mit der ${ }^{18} \mathrm{O}$-Stufe 7 nach der TL-Datierung von KRBETSCHEK wurde im Abschnitt 4.7 schon hingewiesen. Auch von palynologischer Seite wird das Prä-Eem-Alter durch - allerdings sehr spärliche - Funde von Azolla filiculoides wahrscheinlich gemacht (ERD 1994a: 39, 41). Die 
Proben von der Tagebauböschung bei $4 \mathrm{a}$ in Abbildung 1 enthielten zwar nur kleine Bruchstücke von Mikrospongien, die auch von Salvinia stammen können, in der benachbart geteuften Bohrung 1183/72 wurde aber eine bestimmbare Glochidie gefunden. Das äußerst seltene Auftreten von Azolla bietet übrigens auch aus palynologischer Sicht ein Argument gegen die von Lippstreu (1995: 131) vertretene Zuordnung zur Frühsaalezeit (Fuhne, Dömnitz), da "in der Holstein-Warmzeit und der Fuhne-Kaltzeit Azolla stets häufig auftritt und in allen bisherigen Vorkommen der Dömnitz-Warmzeit mit ihren Massenfunden geradezu als kennzeichnend für diesen stratigraphischen Bereich gelten kann" (ERD 1994a: 41).

Weitere Beweise für eine Wärmeperiode im stratigraphischen Niveau zwischen Saale 2 und Warthe 1 sind im Niederlausitzer Braunkohlerevier mehrfach angetroffene Erscheinungen von Entkalkung, Verlehmung und Verbraunung (= Paläobodenbildung). Eine dem Tranitzer Fluviatil sehr ähnlich gelagerte Sedimentfolge mit subarktische Mudden im sandigen unteren Teil erkannte Hellwig (in Cepek, Hellwig \& Nowel 1994: 63) in einer Bohrung unmittelbar südwestlich Guben. Die Schotteranalyse des kiesreichen oberen Teils ergibt hier aber nicht das Spektrum der Lausitzer Neiße, sondern wird dem Einzugsgebiet der Kwisa (Queis) zugeordnet.

Eine weitere dem Tranitzer Fluviatil ähnliche Bildung beschrieb ZieRMANN (in CEPEK et al. 1975: 1059) aus Groß Wusterwitz in Westbrandenburg. Zwischen den Grundmoränen S II und S III sensu CEPEK gelegen und durch Viviparus in liegenden Sanden als postholsteinzeitlich ausgewiesen, befindet sich hier eine $9 \mathrm{~m}$ mächtige limnisch-fluviatile Sedimentfolge mit $3 \mathrm{~m}$ mächtigen Schluffmudden an der Basis. Die Pollenanalyse durch ERD ergab nur subarktische bis arktische Vegetation, das Vorkommen von Azolla filiculoides (nicht umgelagert) belegt ein Alter höher als Eem. Eine nähere Untersuchung wäre hier lohnenswert, ebenso wie bei den in gleicher stratigraphischer Position vermuteten Interglazialschichten der Bohrung Golm 1/71 bei Potsdam (CEPEK et al. 1975: 1069). Die durch ERD (1987) definierte Uecker-Warmzeit von Röpersdorf in Nordostbrandenburg ist zweifelsfrei ein voll entwickelter Interglazialtyp im Saale-Komplex Nordostdeutschlands. Die stratigraphische Einordnung zwischen den Glazialfolgen Saale 1 und Saale 2 ist aber nach dem unter 4.3 und 4.7 Gesagten nicht mehr vertretbar. Neben der von Lippstreu (1995: 134) empfohlenen Einordnung in das Saale-Frühglazial ist aufgrund des mit dem Snaigupele Litauens vergleichbaren Pollenspektrums auch eine mögliche Position zwischen Drenthe und Warthe ernsthaft zu prüfen. Die bisherige Kenntnis der Flora und Fauna legt diese Möglichkeit durchaus nahe. Der das vermutlich gleiche Interglazial in der nur $7 \mathrm{~km}$ entfernten Bohrung Potzlow 1/73 überlagernde Geschiebemergel des Typs SII wäre dann zur Glazialfolge Warthe 2 zu zählen. Im Norden von SachsenAnhalt sind die Warmzeitvorkommen von Kesselsohl und Schützensol noch immer nicht eindeutig geklärt. Кмотн (1995: 164) stellt sie ins Eem, während v. PoBlozkI (1995: 447) eine Zugehörigkeit $\mathrm{zu}$ dem in rund $50 \mathrm{~m}$ tieferem Niveau gelegenen Holstein von Stendal für möglich hält. Die von GLAPA (1970) vorgenommene Einordnung zwischen Drenthe und Warthe bleibt aktuell.

Die Interglaziale im warthezeitlichen Periglazialgebiet Sachsens, Sachsen-Anhalts und Thüringens haben im letzten Jahrzehnt im Widerstreit der Meinungen pro und kontra Intrasaale-Warmzeit eine besondere Rolle gespielt und sollen deshalb etwas ausführlicher betrachtet werden. Hier ist der Langenbogener Boden unbestritten zwischen Drenthe und Warthe positioniert. Er wurde durch KunerT \& Altermann (1965) an der namengebenden Lokalität Langenbogen (Saalkreis) begründet und durch Mania \& Altermann $(1970,2001)$ am Profil Lengefeld-Bad Kösen im mittleren Saaletal eingehend dokumentiert. Mania (1997: 44) kommt zu dem Schluss: "Das Vorkommen der Celtis-Steinkerne hat der Langenbogener Boden gemeinsam mit dem Travertin von Bilzingsleben IV. Weiterhin gibt es deutliche Parallelen zum PK IV Böhmens, Mährens und der Slovakei (LožEK 1964; DемEK, KuKLA et al. 1969; KuKLA 1975), der ebenfalls keine Helicigona banatica-Fauna, aber nur allgemeine europäische Waldkomponente, assoziiert mit wärmeliebenden Steppenarten sowie Früchte von Celtis neopleistocaenica enthält. Der PK IV wird als Hinweis auf eine intrasaalezeitliche Warmzeit angesehen." 
Für den von Fuhrmann (1976) im mittel- und westsächsischen Lössgebiet in den Saale-Komplex gestellten Rittmitzer Boden und Altenburger Boden ist der Versuch einer Korrelation wünschenswert. Die durch EISSMANN (1990: 36; 1998) vorgenommene Zurückstufung in die Prädrenthezeit ist nicht zwingend.

Der Travertin IV von Bilzingsleben (Mania 1994b: 369, 1997: 36) "fällt insofern aus dem Rahmen jungpleistozäner Travertine, als er zahlreiche Steinkerne von Celtis enthält, Syringa josikaea und Pyracantha coccinea vorkommen. Molluskenfunde deuten auf eine Helix pomatia-Fauna hin. Er kann also unmöglich in das Eem gehören, das z.B. durch die Travertine von Burgtonna gut bekannt ist, aber aufgrund seiner tiefen Lage am Hang auch unmöglich dem präsaalezeitlichen Mittelpleistozän zugeordnet werden, obwohl er mit seiner Pflanzenführung nach dahin tendiert. Er kann mit weiteren intrasaalezeitlichen Vorkommen im Saalegebiet ... parallelisiert werden ..." ". Ein anderes solches Vorkommen ist der Untere Travertin von WeimarEhringsdorf. Neben den unter 4.7 bereits genannten absoluten Altersdaten "waren es vor allem die Untersuchungsergebnisse HeINRICHs zum Schmelzband-Differenzierungsquotienten (SDQ) von Arvicola (zuletzt HeInrich 1991: 73), die eine intrasaalezeitliche Einstufung wieder zur Diskussion stellten" (KAHLKE 1994: 365). MANIA (1997: 46) nennt mit Bezugnahme auf Heinrich "eine Form von Arvicola cantianus, die für ein höheres Alter als Eem spricht", und erläutert anhand der Flora und Fauna sowie der speziellen Ehringsdorfer Lagerungsverhältnisse die Parallelen zu Bilzingsleben IV. Der Auffassung von LitT \& Turner (1993: 127), Ehringsdorf "steht momentan zu isoliert, um einen Schlüssel für die Stratigraphie des Mittel- bzw. Jungquartärs zu liefern", kann man nicht folgen.

Auch für das Interglazial von Neumark-Nord im Geiseltal weisen die unter 4.7 genannten Altersdatierungen von 180-210 ka BP auf ein höheres Alter als Eem hin. Mania (1990, 1994a, 1996, 1997) trägt (mit Bezugnahme auf SEIFERT 1990a, b und MAI 1990c, 1992) auch aus lithologischer, floristischer und faunistischer Sicht Argumente für ein solches höheres Alter, nämlich zwischen Drenthe und Warthe, vor. So ist die Molluskenfauna weitgehend mit der von Lengefeld-Bad Kösen iden- tisch einschließlich des charakteristischen Fehlens von Helicigona banatica. Eine weitere Besonderheit ist im Optimum des Interglazials das Vorhandensein eines Acer tataricum-Eichensteppenwaldes. "Es läßt sich also für das Optimum nicht nur warmgemäßigtes Klima, sondern auch ein starker subkontinental-submediterraner Einfluß nachweisen, wie in keinem bisher untersuchten mittel- und jungpleistozänen Interglazial Mitteleuropas ... Die durch die Pollenanalyse ermittelte Vegetationsfolge ... ähnelt der eemzeitlichen Sukzession, hat aber auch einige Besonderheiten, die es vom Eem abgrenzen" (MANIA 1997: 45). Übereinstimmend mit den makrofloristischen Befunden "weist der hochinterglaziale Bereich einen deutlichen Steppeneinschlag auf. Das wird durch das recht häufige Auftreten von Malvaceae, Liliaceae, Artemisia, Compositen, Acer u.a. belegt. Ähnliche Verhältnisse werden in der Odintsovo-Warmzeit ... beobachtet" (SEIFERT 1990b: 152). LiTt (1994: 328) unterstellt Lücken im SEIFERTschen Profil und hält an der Einstufung in das Eem fest; die Auffassung der palynologischen Bearbeiter stehen hier gegeneinander. Nach Mania (1996, 1999: 6) liefert auch die Beschaffenheit der Deckschichtenfolge wichtige Argumente für die Einstufung in den Saale-Komplex. Verbindliche Aussagen zum SDQ von Arvicola für einen direkten Vergleich mit Bilzingsleben IV und Ehringsdorf sind aufgrund bisher zu weniger Funde nicht möglich. Neu ist bei HeInRICH (2001: 136) aber der Nachweis von Apodemus maastrichtiensis, der im zentralen Mitteleuropa außerdem nur aus dem Unteren Travertin von Ehringsdorf und dem noch zu besprechenden Interglazial von Grabschütz bekannt ist. Er wurde bisher niemals in eindeutigen Eemvorkommen Mitteleuropas gefunden und in den Niederlanden dem Hoogeveen-Interstadial innerhalb der Saale-Kaltzeit zugeordnet (das ERD 1978: 111 aufgrund des hohen Gehalts an thermophilen Elementen als echte Warmzeit ansieht).

$\mathrm{Zu}$ kontroversen Schlussfolgerungen kommen die Bearbeiter von Pollenanalyse einerseits und Makroflora sowie Fauna andererseits auch beim Interglazial von Grabschütz. LITT (1990) stellt für das Interglazial von Grabschütz ein Pollenspektrum vor, das bis auf geringe Abweichungen dem der Eem-Warmzeit von Gröbern gleicht. MAI (1990b) 
jedoch weist nach sorgfältiger Analyse der Makroflora wie in Neumark-Nord im Optimum des Interglazials einen Acer tataricum-Eichensteppenwald nach (der in Gröbern nicht vorhanden ist!) sowie einen hervortretenden Anteil thermophiler Arten des sog. "Brasenia-Komplexes" und kommt zusammenfassend zu dem Schluss: "Paläofloristisch steht das Grabschützer Interglazial dem Lichvinund Holstein-Interglazial näher als dem Mikulinooder Eem-Interglazial. Es kann durchaus ein bisher nicht beschriebenes Interglazial in unserem Gebiet sein." LitT (1990: 100) nimmt die Befunde von MAI zur Kenntnis, hält aber "eine chronologische Differenzierung nicht (für) zwingend, da sich chorologische Interpretationsmöglichkeiten anbieten, die den Unterschied der Interglazialfloren von Grabschütz und Gröbern hinreichend erklären." Gegenargumente bringt Mania (1999: 6). Auch die Ostracodenfauna von Grabschütz zeigt nach Fuhrmann \& Pietrzeniuk (1990a, b) deutliche Unterschiede zu stratigraphisch gesicherten Eemvorkommen. "Grabschütz unterscheidet sich von Gröbern und Schönfeld am auffälligsten durch den geringen Anteil von Limnocythere inopinata ... Das auf Grabschütz beschränkte Auftreten von Cypretta eissmanni und Cypridopsis concolor zeigt für dieses Vorkommen ein ungewöhnliches Klima an, wie es heute im mediterranen Raum herrscht. Aufgrund dieser Unterschiede unterstützt die Ostracodenfauna in Übereinstimmung mit der Makroflora das ... voreemzeitliche Alter von Grabschütz." Eine genaue Arvicola-Biostratigraphie ist wegen der zu geringen Anzahl gefundener Exemplare auch in Grabschütz nicht möglich (BeneCKe, Böhme \& Heinrich 1990: 259).

Bezüglich der stratigraphischen Einordnung der Interglaziale von Grabschütz und Neumark-Nord stehen sich Argumente der Intrasaale-WarmzeitBefürworter und -Gegner gegenüber. Für einseitig verabsolutierende Schlussfolgerungen zur Entwicklung der Gesamtregion ist keine ausreichende Grundlage vorhanden. Dem Außenstehenden ist hier vielmehr der weiter vorn zitierte Ermessensspielraum eingeräumt, der hoffentlich durch die weitere Auswertung des Materials von NeumarkNord weiter eingeengt werden kann. Zu den Widersprüchen zwischen Makroflora und Pollenanalyse gibt HEINRICH (in BENECKE et al. 1990: 261) außerdem zu bedenken, "daß die warm- zeitlichen Grundsukzessionen der Vegetation durch den Wegfall von Exoten zur Gegenwart hin qualitativ immer ähnlicher werden. So erscheint zumindest die Frage berechtigt, ob sich hinter sehr ähnlichen oder sogar weitgehend übereinstimmenden pollenanalytisch belegten Grundsukzessionen der Vegetation nicht doch verschiedene Warmzeiten verbergen könnten."

Im Tagebau Schöningen an der östlichen Grenze von Niedersachsen wurde in den letzten Jahren "eine großzyklische Abfolge des Mittel- und Jungquartärs, die überraschend der BilzingslebenFolge gleicht", aufgeschlossen (Mania 1997: 40). Als Wärmeschwankung im Saale-Komplex wird hier die erosiv in Drenthe-Grundmoräne eingeschnittene Schöningen-Folge IV angesehen, die einen mächtigen Bodenkomplex aus zwei Böden enthält, die als Pseudogleye ausgebildet sind.

Im westlichen Niedersachsen hat das Profil Quakenbrück zumindest wissenschaftshistorische Bedeutung: Hier interpretierten Kopp \& WoldstedT (1965) organogene Schichten aus dem Liegenden des Eem-Beckens als zwischen Drenthe und Warthe gehörend und deuteten sie klimastratigraphisch als "ein Mittelding zwischen Interstadial und Interglazial, für das in Ermangelung eines besseren Ausdrucks zunächst die Bezeichnung Großinterstadial verwendet werden könnte." Den eingeschränkten klimastratigraphischen Rang leiteten sie nicht nur vom bis dato fehlenden vollinterglazialen Pollenspektrum in diesem stratigraphischen Niveau ab, sondern auch von der eingeschränkten Ausdehnung der Krefelder Terrasse am Niederrhein und von der Tatsache, dass "eine hochinterglaziale, wärmezeitliche Transgression, wie sie im Holstein- und Eem-Meer vorliegen, in dem Abschnitt zwischen Drenthe und Warthe in Nordwest-Europa fehlt." Andererseits lassen sie aber auch keinen Zweifel daran, dass dieser warme Abschnitt „wahrscheinlich nicht ganz kurz, sondern etwas wärmer und wohl auch etwas länger war" als ein "gewöhnliches Interstadial" und gehen - wie schon WOLDSTEDT (1962) von einem Rücktauen des Inlandeises bis in den Bereich der Åland-Inseln aus. DupHORN et al. (1973: 229) versuchten eine Umdeutung des Quakenbrücker "Großinterstadials" in Holstein, die aber Kopp \& Woldstedt (1965: 41) schon abgelehnt hatten. Nach MEYER (1995: 637) wurde bei 
neueren Bohrarbeiten kein Beweis für ein Intrasaale-Interglazial gefunden.

Am Niederrhein in Nordrhein-Westfalen haben Klostermann, Rehagen \& Wefels (1988) in Gestalt der Vorsealer Schichten im Liegenden von sicherem Eem eine weitere Folge organogener Sedimente angetroffen, "die die Pollenflora einer warmzeitlichen Vegetation mit EMW (überwiegend Quercus), Taxus, Corylus und viel Alnus sowie Hedera und Ilex enthalten." Der Anteil des Eichenmischwaldes liegt bei maximal 15,5\%, der Anteil der thermophilen Laubhölzer zwischen 15 und 20\%. Die stratigraphische Einordnung zwischen Drenthe (Untere Mittelterrasse 3) und Warthe (Krefelder Mittelterrasse) kann als sicher gelten und wird durch KlostermanN (1995) ausdrücklich bestätigt. In das gleiche stratigraphische Niveau stellten KaISER \& SCHÜtrumpF (1960) auch die Kempener und Neuwerker Schichten, die nach ihrer kritischen Überprüfung des Niederrheinischen Quartärs nicht mit den holsteinzeitlichen Krefelder Schichten identisch sind. SCHIRMER (1990: 160) greift die Diskussion auf und stellt die unterschiedlichen Deutungen von Lanser (1983) und KLOSTERMANN (1985) gegenüber; leider ist die paläobotanische Stellung der Kempener Schichten nicht geklärt.

Gestützt wird das Vorhandensein einer Drenthe/ Warthe-Warmzeit am Niederrhein auch durch palaeopedologische Befunde des Lössprofils Rheindahlen bei Mönchengladbach (PAAS 1982); das Liegende des Rheindahlener Bodens wurde auf $239 \pm 26 \mathrm{ka} \mathrm{BP}$, sein Hangendes auf $167 \pm 15 \mathrm{ka} B P$ TL-datiert (Stremme 1989: 190; KLostermanN 1995: 89). Boenigk \& Frechen (1998) legen eine geologische Neubearbeitung der Tongrube Kärlich (Mittelrhein) vor und stellen dabei das Kärlicher Interglazial II (über dem Brockentuff) in ein ähnliches stratigraphisches Niveau (MT IV). Damit ist das nach palynologischen Untersuchungen von URBAN (1983) vermutete Intrasaale-Alter und der durch ERD (1987: 307) vorgenommene Vergleich mit der Uecker-Warmzeit von Röpersdorf und dem Snaigupele Litauens wieder aktuell.

In Schleswig-Holstein deutete Stremme (1989: 192) den Bleichlehm-Palaeosol von Böxlund und den Wenningstedt-Palaeosol von Sylt als Drenthe/Warthe-Wärmeperiode. StePHAN (1995: 5) stellt dies in Frage und schreibt: "Alle neueren Erkenntnisse sprechen gegen eine wärmere Zwischenphase ... Wahrscheinlich gab es eine längere eisfreie Phase mit periglazialen Klimaverhältnissen." Nun, Schleswig-Holstein lag dem westskandinavischen Eiszentrum am nächsten und wurde demzufolge auch zuerst vom kalten Klima des Warthe 1Vorstoßes betroffen. Ist es aber möglich, dass gleichzeitig am nur ca. $400 \mathrm{~km}$ entfernten Niederrhein und im mitteldeutschen Raum interglaziale Vegetation mit Eichenmischwald existierte?

Abschließend noch ein paar Worte zur RügenWarmzeit von Kap Arkona und Hiddensee in Mecklenburg-Vorpommern, die nach den Untersuchungen von CEPEK $(1965,1967)$ und ERD (1970, 1973) über rund 25 Jahre als gesicherte Typuslokalität einer Intrasaale-Warmzeit zwischen den Glazialfolgen Saale II und Saale III sensu CEPEK in Nordostdeutschland galt und auch darüber hinaus in die Quartärstratigraphie Eingang fand. Ihre Altersstellung ist seit den Arbeiten von STEINICH (1988, 1992) umstritten. Für das von CEPEK (1992) und ERD (1992) auf der DEUQUA-Tagung in Kiel engagiert verteidigte Intrasaale-Alter sprechen neben der durch CEPEK geklärten lithologischen Abfolge insbesondere "die Funde der präeemzeitlichen Tertiärrelikte Celtis und Azolla filiculoides in den Cyprinentonen von Hiddensee" (ERD 1992). Eine pollenanalytische Korrelierung mit Holstein oder Eem, aber auch mit der Dömnitzund der Uecker-Warmzeit schließt ERD (1992) aus. Cepek (in Cepek, Hellwig \& Nowel 1994: 48) sieht eine Korrelationsmöglichkeit zwischen den Pollenzonen 3 und 4 der Rügen-Warmzeit und der Pollenzone F des Profils 3/1986 der Chojny-Serie von Bełchatów nach Krupiński, Marks \& SZYNKIEWICZ (1987). Dort ist dann auch die weitere Vegetationsentwicklung dokumentiert, die in den Profilen Kap Arkona und Hiddensee infolge Erosion fehlt. Für die von STEINICH $(1988,1992)$ sowie RüHBERG et al. (1995) diskutierte Zuordnung zum Frühweichsel sprechen die niedrigen absoluten Altersdaten von 27-35 ka BP. ERD (1992) hält eine Intra-Weichsel-Warmzeit in unserem Raum für kaum akzeptabel, während RÜHBERG et al. (1995: 106) Anhaltspunkte für eine solche Einordnung diskutieren und auf das Vorkommen von Azolla filiculoides in offenbar posteemzeitlichen Schichten 
zwischen Rostock und Wismar verweisen. Hier ist auf jeden Fall noch eine eindeutige Klärung erforderlich. Auch eine mögliche Korrelation mit dem intraweichselzeitlichen Krastudy-Interglazial der polnischen Gliederung (in MoJsKi 1995c: 126) ist zu prüfen. Mit Bezug auf die unter 4. diskutierte Grundmoränenstratigraphie stellt sich dabei auch die Frage, ob der unterlagernde ostbaltische Geschiebemergel dem Saale II sensu CEPEK oder dem warthezeitlichen Hennstedt-Till entspricht.

\subsection{Schlussfolgerungen}

1. Im Gebiet zwischen der Russischen Tiefebene und dem Niederrhein gibt es eine größere Anzahl warmzeitlicher Profile, die als Beweis für das Vorhandensein einer Wärmeperiode innerhalb des Saale-Komplexes, und zwar zwischen dem saale-(drenthe-) zeitlichen und dem warthezeitlichen Vereisungszyklus, gelten können. Diese Aussage wird in unterschiedlichem Maße durch geologische, palynologische, makrofloristische und faunistische Befunde sowie absolute Altersdaten gestützt. Es wird als nicht sinnvoll angesehen, diese Befunde zu negieren, wenn im engeren eigenen Arbeitsgebiet bisher keine diesbezüglichen Fakten bekannt wurden.

2. Die Aussagen zum klimastratigraphischen Rang der Wärmeperiode sind differenziert zu betrachten. In Osteuropa (Odintsovo, Shklov, Snaigupele) kann eine interglaziale Entwicklung als sicher gelten. In Ost- und Mittelpolen sind interglaziale (Lubawa) oder zumindest über ein normales Interstadialklima hinaus gehende Verhältnisse (Grabówka, Bełchatów) nachgewiesen. Aber auch in Nordostbrandenburg (Uecker), in Mitteldeutschland (Bilzingsleben IV, Ehringsdorf, Lengefeld-Bad Kösen, Neumark-Nord und Grabschütz) sowie am Rhein (Vorsealer, Kärlich II) ist interglaziale Entwicklung nachgewiesen, die stratigraphische Stellung aber z.T. umstritten. Andere Profile, wie das Tranitzer Fluviatil in der Niederlausitz, Groß Wusterwitz in Westbrandenburg oder die Kempener und Neuwerker Schichten am Rhein, sind beim gegenwärtigen Kenntnisstand nicht sicher als Interglazial oder Interstadial zu definieren.

3. Eine Parallelisierung oder Korrelation der einzelnen Vorkommen ist noch mit großen Schwie- rigkeiten verbunden, zumal z.T. nur unvollständige Pollenspektren und z.T. nur makrofloristische oder faunistische Aussagen vorliegen. Als relativ wahrscheinlich kann eine Korrelation zwischen Snaigupele (Litauen), Lubawa (Polen) Uecker (Nordostbrandenburg) und evtl. Kärlich II (Mittelrhein) gelten. Eine andere vergleichbare Linie bilden die von MANIA bearbeiteten Vorkommen Bilzingsleben IV, Unterer Travertin von Ehringsdorf und Lengefeld-Bad Kösen (Thüringen) sowie Neumark-Nord (Geiseltal) und Grabschütz (Westsachsen) mit dem charakteristischen Acer tataricum-Eichensteppenwald. Eine Korrelation des Pollenspektrums von Neumark-Nord mit dem der Uecker-Warmzeit ist nicht möglich. Auch das Fehlen oder zumindest sehr spärliche Vorkommen von Azolla filiculoides in NeumarkNord gegenüber etwas häufigerem Vorkommen in der Uecker-Warmzeit weist darauf hin, dass hier zwei unterschiedliche Medien existieren. Gemeinsam hat Neumark-Nord die geringen oder fehlenden Azolla-Funde mit dem Tranitzer Fluviatil und der Chojny-Serie von Bełchatów. Die ${ }^{18} \mathrm{O}$-Stufe 7 umfasst einen relativ langen Zeitraum und ist, wie auch der Kurvenverlauf in der Abbildung 6 erkennen läßt, nicht gleichmäßig ausgestattet. So, wie es in vollständigen Profilen des Odintsovo eigentlich zwei voneinander getrennte Warmzeiten gibt (GlasowskiOptimum und Roslavlski-Optimum), kann es vielleicht auch in Mitteleuropa zwei unterschiedliche Entwicklungen in der Vertikalen geben. ERD (1978: 111; 1987: 309) deutet diese Problematik bei den Korrelationsversuchen mit dem Odintsovo bereits an.

4. Die Vergabe eines verbindlichen Namens für den betreffenden Zeitabschnitt ist zum gegenwärtigen Zeitpunkt nicht minder schwierig, nachdem sich die Verallgemeinerung der Bezeichnungen "Treene-Warmzeit" und "Rügen-Warmzeit" als nicht von Dauer erwiesen hat. So sollte der Rat von Woldstedt (1928: 212) Gültigkeit behalten: "Zunächst lokale Gliederung und lokale Bezeichnungen, dann erst der Versuch einer Parallelisierung und die Einführung allgemeingültiger Namen." Als integrativer Rahmen kann die neutrale Bezeichnung "Drenthe/WartheWärmeperiode" verwendet werden. 


\section{Schriftenverzeichnis}

Bassinot, F. V., Labeyrie, L. D., Vincent, E., Quidelleur, X., Shackleton, N. J. \& Lancelot, Y. (1994): The astronomical theory of climate and the age of Brunhes-Matuyama magnetic reversal. - Earth and Planetary Science Letters, 126: 91-108; Amsterdam.

BEHRENDT, L. (1998): Vergleich der Grundmoränen des Saale-Glazials der Niederlausitz mit denen Nordwestdeutschlands, der Niederlande und Polens. Brandenburgische Geowiss. Beitr., 5 (2): 29-41; Kleinmachnow.

BendA, L. [Hrsg.](1995): Das Quartär Deutschlands. 408 S., 95 Abb., 30 Tab.; Berlin/Stuttgart.

Benecke, N., Böhme, G. \& Heinrich, W.-D. (1990): Wirbeltierreste aus interglazialen Beckensedimenten von Gröbern (Kr. Gräfenhainichen) und Grabschütz (Kr. Delitzsch). - Altenburger nat. wiss. Forsch., 5: 231-281; Altenburg.

Ber, A. (2000): Pleistocene of North-Eastern Poland and neighbouring areas against crystalline and sedimentary basement. - Prace Panstwowego Instytutu Geologicznego, 170: 89 S.; Warszawa.

BerendT, G. (1886): Zur Geognosie der Altmark. - Jb. d. kgl. preuß. geol. Landesanst., 1886: 105-115; Berlin.

BoenigK, N. \& Frechen, M. (1998): Zur Geologie der Deckschichten von Kärlich/Mittelrhein. - Eiszeitalter u. Gegenwart, 48: 38-49; Hannover.

BönIsCH, R. (1991): Neue quartärgeologische Modelle für Eembecken in der Niederlausitz. - Tagungsmaterial 38. Jahrestagung GGW: 95-97; Berlin.

Bronger, A. (1999): Löss-Paläoboden-Sequenzen Zentralasiens als Indikatoren einer globalen Klimageschichte des Quartärs? - Eiszeitalter u. Gegenwart, 49: 35-54; Hannover.

- \& Heinkele, T. (1989): Paleosol sequences as witnesses of Pleistocene climatic history. - In: A. Bronger \& J. Catt [Eds.]: Paleopedology - Nature and Application of Paleosols. - Catena Supplement, 16: 163-186; Cremlingen.

BRUNNER, H. (1961): Eisrandlagen und Vereisungsgrenzen im Hohen Fläming. - Beih. Geologie, 31: 1-74; Berlin.

Caspers, G., Jordan, H., Merkt, J., Meyer, K.-D., Mưller, H. \& Streif, H. (1995): III. Niedersachsen. - In: BendA, L. [Hrsg.]: Das Quartär Deutschlands: 23-58; Berlin/Stuttgart.

Cepek, A.G. (1965): Zur Gliederung des Mittel-Pleistozäns im norddeutschen Flachland. - Eiszeitalter u. Gegenwart, 16: 255; Öhringen.

- (1967): Stand und Probleme der Quartärstratigraphie im Nordteil der DDR. - Ber. dt. Ges. geol. Wiss., A, Geol. Paläont., 12 (3/4): 375-404; Berlin.
- (1968): Quartär - In: Grunariß der Geologie der DDR, Bd. 1: 385-420; Berlin.

- (1969): Zur Bestimmung und stratigraphischen Bedeutung der Dolomitgeschiebe in den Grundmoränen im Nordteil der DDR. - Geologie, 18 (6): 657-673; Berlin.

- (1975): Information über den Stand der stratigraphischen Gliederung des Quartärs in der DDR. IUGS-UNESCO Intern. Geol. Correl. Progr., Projekt 73/1/24, Quat. Glaciations in the Northern Hem., Report No. 2: 67-74; Prague.

- (1979): Zu einigen Aufgaben der methodischen Angleichung der Grundmoränenstratigraphie in der VR Polen und in der DDR. - Acta Universitatis Nicolai Copernici, Geografia XIV, 46: 15-20; Toruń.

- (1986): Quaternary Stratigraphy of the German Democratic Republic. - In: V. ŠIBRAVA, D.Q., Bowen \& G.M. Richmond [Eds.]: Quaternary Glaciations in the Northern Hemisphere. - Quat. Science Rev., 5: 359-364; Oxford.

- (1991): Zur Einstufung der Geschiebemergel im Profil Schönfeld, Kreis Calau. - In: R. \& U. STRIEGLER [Hrsg.]: Eem von Schönfeid I. - Natur u. Landschaft in der Niederlausitz, Sonderh.: 41-47; Cottbus.

- (1992): Zur Begründung der Rügen-Warmzeit und ihrer Korrelation. - Tagungsprogr. u. Kurzfass. zur 26. Tagung der DEUQUA, 12.-21.9.1992 in Kiel: 31; Kiel (Deutsche Quartärvereinigung).

- , Hellwig, D., Lippstreu, L., Lohde, H., Ziermann, H. \& Zwirner, R. (1975): Zum Stand der Gliederung des Saale-Komplexes im mittleren Teil der DDR. - Z. geol. Wiss., 3 (8): 1049-1075; Berlin.

- \& ERD, K. (1980): Classification and stratigraphy of the Holsteinian and Saalian Complex in the Quaternary of the German Democra ic Republic. - IUGSUNESCO Intern. Geol. Correl. Progr., Project 73/1/24, Quat. Glaciations in the Northern Hem., Report No. 7: 50-56; Prague.

— \& Nowel, W. (1991): Zum Pleistozän im Raum Klinge-Dubrau (östliche Niederlausitz), ein Typusgebiet für den Saale-Komplex. - Z. geol. Wiss., 19 (3): 289-316; Berlin.

— , Hellwig, D. \& Nowel, W. (1994): Zur Gliederung des Saale-Komplexes im Niederlausitzer Braunkohlenrevier. - Brandenburgische Geowiss. Beitr., 1 (1): 43-83; Kleinmachnow.

Czerwonka, J.A. \& Krzyszkowski, D. (1992a): Till characteristics and stratigraphy in the Kleszczów Graben (Central Poland). - Quaternary Studies in Poland, 11: 43-64; Poznań.

— \& KrzYszKowski, D. (1992b): Pleistocene Stratigraphy of the Central Part of Silesian Lowland, Southwestern Poland. - Bull. Polish Acad. Science, Earth Science, 40 (3): 203-233; Warszawa. 
- \& Wittek, B. (1977): Granulometric and petrographic studies of tills of South Western Poland. Biul. Inst. Geol., 305: 45-58; Warszawa.

Demek, J. \& Kukıa, I. (1969): Periglazialzone, Löss und Paläolithikum der Tschechoslowakei. - 158 S.; Brno.

Duphorn, K., Grube, F., Meyer, K.-D., Streif, H. \& VINKEN, R. (1973): State of Research on the Quaternary of the Federal Republic of Germany, A. Area of the Scandinavian Glaciation, 1. Pleistocene and Holocene. - Eiszeitalter u. Gegenwart, 23/24: 222250; Öhringen.

Ehlers, J. (1983): The Glacial History of North-West Germany. - In: EHLers, J. [Ed.]: Glacial deposits in North-West Europe: 229-238; Rotterdam.

- (1992): Origin and distribution of red tills in North Germany. - Sveriges Geologiska Undersökning, Ser. Ca 81: 97-105; Stockholm.

- (1995a): II. Hamburg. - In: BendA, L. [Hrsg.]: Das Quartär Deutschlands: 14-22; Berlin/Stuttgart.

- (1995b): Geologische Karte von Hamburg 1:25000, Erläuterungen zu Blatt Nr. 2425 Hamburg. - Geologisches Landesamt: 164 S.; Hamburg.

- , Meyer, K.-D. \& Stephan, H.-J. (1984): The PreWeichselian glaciations of North-West Europe. Quatern. Science Rev., 3: 1-40; Oxford.

— , Kozarski, S. \& Gibbard, P. (1995): Glacial deposits of North-East Europe: general overview. In: Ehlers, J., Kozarski, S. \& Gibbard, P. [Eds.]: Glacial deposits in North-East Europe: 547-552; Rotterdam.

EIssmann, L. (1975): Das Quartär der Leipziger Tieflandsbucht und angrenzender Gebiete um Saale und Elbe - Modell einer Landschaftsentwicklung am Rand der europäischen Kontinentalvereisung. Schriftenr. geol. Wiss., 2: 1-263; Berlin.

- (1990): Das mitteleuropäische Umfeld der Eemvorkommen des Saale-Elbe-Gebietes und Schlußfolgerungen zur Stratigraphie des jüngeren Quartärs. - Altenburger nat. wiss. Forsch., 5: 11-48; Altenburg.

- (1994): Grundzüge der Quartärgeologie Mitteldeutschlands (Sachsen, Sachsen-Anhalt, Südbrandenburg, Thüringen). - Altenburger nat. wiss. Forsch., 7: 55-135; Altenburg.

- (1995): VIII. Sachsen. - In: BendA, L. [Hrsg.]: Das Quartär Deutschlands: 171-198; Berlin/Stuttgart.

- (1997): Das quartäre Eiszeitalter in Sachsen und Nordostthüringen. - Altenburger nat. wiss. Forsch., 8: 1-98; Altenburg.

- (1998): Das Quartär Nord- und Mitteldeutschlands (Zusammenfassung). - TERRA NOSTRA, Schriften der Alfred-Wegener-Stiftung 98/3, Geo-Berlin '98, Gemeinsame Jahrestagg. d. DGG, DMG, GGW \& Pal.Ges., 6.-9. Okt. 1998 TU Berlin, Progr. u. Zusammenfass. d. Tagungsbeitr., V 67; Berlin.
- \& LitT, T. [Hrsg.] (1994): Das Quartär Mitteldeutschlands. Ein Leitfaden und Exkursionsführer. Mit einer Übersicht über das Präquartär des SaaleElbe-Gebietes. - Zur 27. DEUQUA-Tagung in Leipzig. - Altenburger nat. wiss. Forsch., 7; 458 S.; Altenburg.

ERD, K. (1970): Pollenanalytical classification of the Middle Pleistocene in the German Democratic Republic. Palaeogr., Palaeoclimatol., Palaeoecol., 8: 129-145; Amsterdam.

- (1973): Pollenanalytische Gliederung des Pleistozäns der Deutschen Demokratischen Republik. - Z. geol. Wiss., 1 (9): 1087-1103; Berlin.

- (1978): Pollenstratigraphie im Gebiet der skandinavischen Vereisungen. - Schriftenr. geol. Wiss., 9: 99-119; Berlin.

- (1987): Die Uecker-Warmzeit von Röpersdorf bei Prenzlau als neuer Interglazialtyp im Saale-Komplex der DDR. - Z. geol. Wiss., 15 (3): 297-313; Berlin.

- (1992): Pollenanalytische Charakteristik und Abgrenzung der Cyprinentone von Rügen und Hiddensee. - Tagungsprogr. u. Kurzfass. zur 26. Tagung der DEUQUA 12.-21.9.1992 in Kiel: 36; Kiel (Deutsche Quartärvereinigung).

- (1994a): Palynologische Aussagen zum Holsteinund Saale-Komplex im Gebiet des Tagebaus Jänschwalde. - Brandenburgische Geowiss. Beitr., 1 (1): 36-42; Kleinmachnow.

- (1994b): Zum Gedenken an Alexander Georg Cepek (27.11.1929 - 9.5.1994). - Brandenburgische Geowiss. Beitr., 1 (1): 127-128; Kleinmachnow.

Fumrmann, R. (1976): Die stratigraphische Stellung der Löße in Mittel- und Westsachsen. - Z. geol. Wiss., 4 (9): 1241-1270; Berlin.

- \& Pietrzeniuk, E. (1990a): Die Ostrakodenfauna des Interglazials von Gröbern (Kreis Gräfenhainichen). - Altenburger nat. wiss. Forsch., 5: 168193; Altenburg.

- (1990b): Die Ostrakodenfauna des Interglazials von Grabschütz (Kreis Delitzsch). - Altenburger nat. wiss. Forsch., 5: 202-227; Altenburg.

FuhrmanN, U. (1983): Kalium-Argon-Untersuchungen an neogenen Vulkaniten des Rheinischen Schildes. Diss. Univ. Heidelberg: 157 S.; Heidelberg.

Gauger, W. \& Meyer, K.-D. (1970): Ostbaltische Geschiebe (Dolomite, Old-Red-Sandsteine) im Gebiet zwischen Lüneburg und Uelzen. - Der Geschiebesammler, 5 (1): 1-12; Hamburg.

GlapA, H. (1970): Zur Stratigraphie des Pleistozäns im Gebiet der Letzlinger Heide und im Elbtal nördlich Magdeburg. - Geologie, 19 (2): 206-242; Berlin.

- (1971): Warthezeitliche Eisrandlagen im Gebiet der Letzlinger Heide. - Geologie, 20 (10): 1087-1110; Berlin. 
Goretsky, G. I., Chebotareva, N. S. \& Shick, S. M. [Eds.] (1982): Moscow ice sheet of East Europe. Academa of Sciences of the USSR, Commission for Studies of the Quaternary Period, XI. INQUA Congress: 240 S.; Moskwa.

Grube, F. (1967): Die Gliederung der Saale-(Riß-) Kaltzeit im Hamburger Raum. - Fundamenta, B 2: 168-195; Köln/Graz.

Gruner, H. (1889): Erläuterungen zur Geologischen Karte von Preußen und den Thüringischen Staaten, Blatt Tangerhütte und Blatt Tangermünde. - Berlin (Kgl. Preuß. Geol. Landesanst.).

HeINRICH, W.-D. (1991): Zur biostratigraphischen Einordnung der Fundstätte Bilzingsleben an Hand fossiler Kleinsäugetiere. - Veröff. Landesmus. Vorgesch. Halle, 44: 71-79; Berlin.

- (2001): Kleinsäugerreste aus interglazialen Ablagerungen von Neumark-Nord. Vorläufige Mitteilung. - Praehistoria Thuringica, 6/7: 132-138; Artern.

Hellwig, D. (1975): Fluviatile Bildungen innerhalb des Saale-Komplexes im Raum Cottbus-Forst. - Z. geol. Wiss., 3 (8): 1077-1090; Berlin.

- (1992): Erste Funde von Artefakten im intrasaalezeitlichen Tranitzer Fluviatil in Klinge bei Cottbus. - Vortrag zur 26. DEUQUA-Tagung 1992; Kiel (unveröff.).

— , Kühner, R. \& Nowel, W. (1994): Exkursionshalt A 1/2: Ostrandschlauch Tagebau Jänschwalde, ca. $2 \mathrm{~km}$ westl. Mulknitz. - Altenburger nat. wiss. Forsch., 7: 156, 160, 164-166; Altenburg.

Hucke, K. (1922): Geologie von Brandenburg. - 352 S.; Stuttgart.

Illies, H. (1952): Eisrandlagen und eiszeitliche Entwässerung in der Umgebung von Bremen. - Abh. naturwiss. Verein Bremen, 33: 19-56; Bremen.

JäGER, K.-D. (1999): Travertin- und Loess-Interglaziale zwischen Thüringen und Mähren. - Vortrag z. Symposium "Quartär-Stratigraphie: Methoden - Gliederungen - Korrelationen" am 12.6.1999, TU Berlin, (unveröff.).

Jordan, H. (1975): Geologische Karte von Niedersachsen 1:25000, Erläuterungen zu Blatt Großburgwedel Nr. 3525. - 93 S., 1 Kt.; Hannover (Niedersächs. Landesamt f. Bodenforsch.).

KAHLKE, R.-D. (1994): Exkursionspunkt B 2/2: Travertinbrüche Weimar-Ehringsdorf. - Altenburger nat. wiss. Forsch., 7: 362-366; Altenburg.

Kaiser, K. \& Schưtrumpf, R. (1960): Zur Gliederung mittel- und jungpleistozäner Schichten in der Niederrheinischen Bucht. - Eiszeitalter u. Gegenwart, 11: 166-185; Öhringen.

Kaunhowen, F., Keilhack, K. \& Meyer, E. (1923): Erläuterungen zur Geologischen Karte von Preußen und benachbarten Bundesstaaten, Blatt Lübbenau. 40 S., 1 Kt.; Berlin (Preuß. Geol. Landesanst.).
Keller, G. (1953): Die Beziehung des Rehburger Stadiums südlich Ankum (Kr. Bersenbrück) zur saaleeiszeitlichen Grundmoräne. - Eiszeitalter u. Gegenwart, 3: 58-64; Öhringen.

Klostermann, J. (1985): Versuch einer Neugliederung des späten Elster- und des Saale-Glazials der Niederrheinischen Bucht. - Geol. Jb., A 83: 3-46; Hannover.

- (1995): IV. Nordrhein-Westfalen. - In: BENDA, L. [Hrsg.]: Das Quartär Deutschlands: 59-94; Berlin/Stuttgart.

— , Rehagen, H.-W. \& Wefels, U. (1988): Hinweise auf eine saalezeitliche Warmzeit am Niederrhein. Eiszeitalter u. Gegenwart, 38: 115-127; Hannover.

KNOTH, W. (1995): VII. Sachsen-Anhalt. - In: L. BENDA [Hrsg.]: Das Quartär Deutschlands: 148-170; Berlin/Stuttgart.

Kopp, E. \& Woldstedt, P. (1965): Über den Charakter der Wärmezeit zwischen Drenthe- und Warthe-Stadial in Norddeutschland. - Eiszeitalter u. Gegenwart, 16: 37-46; Öhringen.

KraSNOV, I.I. (1978): Stratigraphische Korrelation der Quartärablagerungen im östlichen Gebiet der fennoskandischen Vereisungen. - Schriftenr. geol. Wiss., 9: 69-79; Berlin.

KRUPIŃSKI, K.M. \& MARKS, L. (1986): Interglacial sediments at Losy, Mazury Lakeland. - Bull. Polish Acad. Science, Earth Science, 34 (4): 375-386, Warszawa.

— , Marks, L. \& Szynkiewicz, A. (1987): Three New Sites of the Middle Pleistocene Fossil Floras from the Bełchatów Mine, Central Poland. - Bull. Polish Acad. Science, Earth Science, 35 (4): 359-377; Warszawa.

KRZYSZKOwsKI, D. (1993): The Wartanian Siedlec Sandur (Zedlitzer Sander) southwards the Trzebnica Hills, Silesian Lowland, Southwestern Poland: re-examination after fifty years. - Eiszeitalter u. Gegenwart, 43: 53-66; Hannover.

KuKLA, G. J. (1975): Loess stratigraphy of Central Europe. - In: Butzer, K.W. [Ed.]: After the Australopithecines: stratigraphy, ecology and culture change in the Middle Pleistocene: 99-188; Mouton.

Kunert, R. \& Altermann, M. (1965): Das Pleistozän zwischen Saale und Wipper. - Geologie, 14 (5/6): 520-553; Berlin.

LANG, H. D. (1983): Aufbau, Alter und regionale Einordnung der Endmoränen im Gebiet des Falken-Berges bei Fallingbostel (Niedersachsen). - Eiszeitalter u. Gegenwart, 33: 31-43; Hannover.

- (1993): Neue Ergebnisse quartärgeologischer Untersuchungen im Gebiet der "Falkenberg-Endmoräne". Eiszeitalter u. Gegenwart, 43: 23-28; Hannover.

Lanser, K.-P. (1983): Die Krefelder Terrasse und ihr Liegendes im Bereich Krefeld. - Diss. Univ. Köln: 241 S.; Köln. 
LiedTKE, H. (1981): Die nordischen Vereisungen in Mitteleuropa. - Forschungen zur deutschen Landeskunde, 204: 307 S.; Trier.

LindneR, L. (1984): An outline of Pleistocene chronostratigraphy in Poland. - Acta Geologica Polonica, 34 (1-2): 27-49; Warszawa.

- (1988): Stratigraphy and extents of Pleistocene continental glaciations in Europe. - Acta Geologica Polonica, 38 (1-4): 63-83; Warszawa.

- (1991): Stratigraphy of main Pleistocene loess horizons and paleosols in mid-eastern Europe. - Acta Geologica Polonica, 41 (1-2): 85-100; Warszawa.

- , DzierżeK, J., Lamparski, Z., Marks, L. \& NityCHORUK, J. (1995): Zarys stratigrafii czwartorzędu Polski; główne poziomy osadów glacjalnych i interglacjalnych oraz ich rozprzestrzenienie. - Przeglad Geologiczny, 43 (7): 586-591; Warszawa.

- \& Grzybowski, K. (1982): Middle-Polish glaciations (Odranian, Wartanian) in southern central Poland. Acta Geologica Polonica, 32 (3-4): 191-206; Warszawa.

- \& MarciniaK, B. (1998): The occurence of four interglacials younger than the Sanian 2 (Elsterian 2) Glaciation in the Pleistocene of Europe. - Acta Geologica Polonica, 48 (3): 247-263; Warszawa.

- \& MARKS, L. (1999): New approach to stratigraphy of palaeolake and glacial sediments of the younger Middle Pleistocene in mid-eastern Poland. - Geological Quarterly, 43 (1): 1-8; Warszawa.

— , Wojtanowicz, J. \& Bogutsky, A.B. (1998): Main stratigraphical units of the Pleistocene in southeastern Poland and the northwestern Ukraine, and their correlation in Western and mid-eastern Europe. Geological Quarterly, 42 (1): 73-86; Warszawa.

Linke, G., Katzenberger, O. \& Grün, R. (1985): Description and ESR dating of the Holsteinian Interglaciation. - Quaternary Science Rev., 4: 319-331; Oxford.

Lippstreu, L. (1995): VI. Brandenburg. - In: L. BendA [Hrsg.]: Das Quartär Deutschlands: 116-139; Berlin/Stuttgart.

- , Hermsdorf, M., Sonntag, A. \& Thieke, H.U. (1994): Zur Gliederung der quartären Sedimentabfolgen im Niederlausitzer Braunkohlentagebau Jänschwalde und in seinem Umfeld - Ein Beitrag zur Gliederung der Saale-Kaltzeit in Brandenburg. Brandenburgische Geowiss. Beitr., 1 (1): 15-35; Kleinmachnow.

LiтT, T. (1990): Pollenanalytische Untersuchungen zur Vegetations- und Klimaentwicklung während des Jungpleistozäns in den Becken von Gröbern und Grabschütz. - Altenburger nat. wiss. Forsch., 5: 92105; Altenburg.

- (1994): Zur stratigraphischen Einstufung des Interglazials von Neumark-Nord aufgrund neuer pollenanalytischer Befunde. - Altenburger nat. wiss. Forsch., 7: 328-333; Altenburg.
- \& Turner, C. (1993): Arbeitsergebnisse der Subkommission für Europäische Quartärstratigraphie: Die Saalesequenz in der Typusregion (Berichte der SEQS 10). - Eiszeitalter u. Gegenwart, 43: 125-128; Hannover.

LožEK, V. (1964): Mittel- und jungpleistozäne Lößserien in der Tschechoslowakei und ihre Bedeutung für die Lößstratigraphie Mitteleuropas. - In: Report of the VI. Intern. Congress an Quaternary Warsaw 1961, 4: 525-549; Lódź.

MAI, D. H. (1990a): Die Flora des Interglazials von Gröbern (Kreis Gräfenhainichen). - Altenburger nat. wiss. Forsch., 5: 106-115; Altenburg.

- (1990b): Die Flora des Interglazials von Grabschütz (Kreis Delitzsch). - Altenburger nat. wiss. Forsch., 5: 116-137; Altenburg.

- (1990c): Die Flora des Interglazials von NeumarkNord, Kr. Merseburg (vorläufige Mitt.). - Veröff. Landesmus. Vorgesch. Halle, 43: 159-160; Berlin.

- (1992): Über einige Steppen- und Salzpflanzen in sächsisch-thüringischen Interglazialen und ihre vegetationsgeschichtliche Bedeutung. - Gleditschia, 20: 57-85; Berlin.

MaKowsKa, A. (1977): Poziom interglacjalny wśród osadów zlodowacenia środkowopolskiego w Dolinie Dolnej Wisły. - Kwart. Geol., 21 (4): 769787; Warszawa.

Manhenke, V. \& Grosse, R. (1970): Beitrag zur Kenntnis des Pleistozäns nordwestlich von Leipzig (Hatzfeld). - Geologie, 19 (8): 909-930; Berlin.

Mania, D. (1990): Stratigraphie, Ökologie und mittelpaläolithische Jagdbefunde des Interglazials von Neumark-Nord (Geiseltal). - Veröff. Landesmus. Vorgesch. Halle, 43: 9-130; Berlin.

- (1994a): Das Interglazialvorkommen von NeumarkNord. - Altenburger nat. wiss. Forsch., 7: 324-327; Altenburg.

- (1994b): Exkursionspunkt B 2/4: Mittelpleistozän und Altpaläolithikum von Bilzingsleben. - Altenburger nat. wiss. Forsch., 7: 367-374; Altenburg.

- (1996): Das Interglazial von Neumark-Nord (Geiseltal) - Zum Untersuchungsstand 1994. - Tübinger Monographien zur Urgeschichte, 11: 217-229; Tübingen.

- (1997): Einleitung: Bilzingsleben - 25 Jahre Homo erectus im Saale-Elbe-Gebiet. Das Quartär des Saalegebietes und des Harzvorlandes unter besonderer Berücksichtigung der Travertine von Bilzingsleben - Ein Beitrag zur zyklischen Gliederung des eurasischen Quartärs. - In: MANIA, D. [Hrsg.]: Bilzingsleben V, Homo erectus - seine Kultur und Umwelt: 17-103; Bad Homburg, Leipzig.

- (1999): 125000 Jahre Klima- und Umweltentwicklung im mittleren Elbe-Saale-Gebiet. - Hercynia, N.F., 32: 1-97; Halle, Leipzig. 
- \& Altermann, M. (1970): Zur Gliederung des Jung- und Mittelpleistozäns im mittleren Saaletal bei Bad Kösen. - Geologie, 19 (10): 1161-1184; Berlin.

- (2001): Die Deckschichten von Lengefeld-Bad Kösen im mittleren Saaletal - ein Typusprofil für die Quartärstratigraphie. - Praehistoria Thuringica, 6/7: 103-131; Artern.

MarcineK, J. (1961): Über die Entwicklung des Baruther Urstromtals zwischen Neiße und Fiener Bruch. Wiss. Z. Humboldt-Univ. Berlin, math.-nat. R., 10: 13-46; Berlin.

Menke, B. (1970): Ergebnisse der Pollenanalyse zur Pleistozänstratigraphie und zur Pliozän-Pleistozän-Grenze in Schleswig-Holstein. - Eiszeitalter u. Gegenwart, 21: 5-21; Öhringen.

- (1985): Eem-Interglazial und Treene-Warmzeit in Husum/Nordfriesland. - Geol. Jb., A 86: 63-99; Hannover.

Mensching, H. (1969): Landformen im Kartenbild. Topographisch-Geomorphologische Kartenproben 1:25000, Gruppe I: Norddeutsches Flachland. Kartenprobe 5: Altmoränenlandschaft der Dammer Berge, nordwestlich des Dümmer. - Geomorphologische Beschreibung: 5-10; Braunschweig.

MeYER, K.-D. (1995): Stop 31: Holdorf-Quakenbrück glacier-tongue basin. - In: Schirmer, W. [Ed.]: Quaternary field trips in Central Europe, 2: 637-638; München.

Mojski, J. E. (1985): Geology of Poland, Volume I stratigraphy, part 3b Cainocoic, Quaternary. - 248 S.; Warszawa (Wyd. Geol.).

- (1995a): The Warta unit in the Pleistocene stratigraphy of Poland. - Acta Geogr. Łódźiensia, 68: 213 225; Łódź.

- (1995b): Pleistocene glacial events in Poland. - In: Ehlers, J., Kozarski, S. \& Gibbard, P. [Eds.]: Glacial deposits in North-East Europe, 287-292: Rotterdam.

- (1995c): Baltic traverse. Overview Poland. - In: Schirmer, W. [Ed.]: Quaternary field trips in Central Europe, Vol. 1: 125-128; München.

Moskwiтin, A. I. (1960): Über warme und kühlere Interglaziale in der UdSSR. - Ber. geol. Ges. DDR, 5 (1/2): 5-20; Berlin.

Múller, A. (1988): Das Quartär im mittleren Elbegebiet zwischen Riesa und Dessau. - Diss. Univ. Halle, (unveröff.).

Nitychoruk, J., Hoefs, J. \& Schneider, J. (1999): Klima-Änderungen im Pleistozän: Isotopenuntersuchungen an fossilen Seesedimenten aus dem Holstein-Interglazial Ost-Polens. - Eiszeitalter u. Gegenwart, 49: 21-34; Hannover.

Nowel, W. (1965): Untersuchungen über die Lagerungsverhältnisse des Quartärs im westlichen und mittleren Teil des Lausitzer Braunkohlen-Kernreviers. - Dipl.-Arb. Geol. Inst. Bergakad. Freiberg: 198 S; Freiberg/Sa. (unveröff.).

- (1982-84): Die geologische Entwicklung des Bezirkes Cottbus, Teil III: Das Quartär. - Natur und Landschaft Bez. Cottbus NLBC, 4: 3-38, 5: 3-26, 6: 3-33; Cottbus.

- (1991): Eine neue quartärgeologische Übersichtskarte des ehemaligen Bezirkes Cottbus im Maßstab 1:200000. - Petermanns Geogr. Mitt., 135 (1): $67-$ 73; Gotha.

- (1992): Geologische Übersichtskarte des Niederlausitzer Braunkohlenreviers im Maßstab 1:200 000. - Lausitzer Braunkohle AG (LAUBAG); Senftenberg.

- (1996): Aktuelle Bemerkungen zur Gliederung des Saale-Komplexes im Quartär der Niederlausitz. Natur und Landschaft in der Niederlausitz, 17: 5477; Cottbus.

- (1998): Zeugen der Eiszeit in der Lausitz. - Lausitzer Braunkohle AG (LAUBAG): 34S.; Senftenberg.

- \& Cepek, A.G. (1988): Das Pleistozän von KlingeDubrau (Kr. Forst). - Natur und Landschaft Bez. Cottbus NLBC, 10: 3-20; Cottbus.

- , Bönisch, R., Schneider, W. \& Schulze, H. (1994): Geologie des Lausitzer Braunkohlenreviers. - Lausitzer Braunkohle AG (LAUBAG); Senftenberg.

PAAs, W. (1982): Paläoböden des Niederrheins - Geol. Jb., F 14: 228-239; Hannover.

PICARD, K. (1959): Gliederung pleistozäner Ablagerungen mit fossilen Böden bei Husum/Nordsee. $-\mathrm{N}$. Jb. Geol. Pal., Mh., 6: 259-272; Stuttgart.

PICARD, K. (1960): Zur Untergliederung der "Saalevereisung" im Westen Schleswig-Holsteins. - Z . deutsch. geol. Ges., 112: 316-325; Hannover.

Poвlozki, B.v. (1972): Lihofazieskarte Quartär im Maßstab 1:50 000, Blatt 1964 Stendal; Berlin (Zentrales Geologisches Institut).

- (1973): Lithofazieskarte Quartär im Maßstab 1:50 000, Blatt 1963 Klötze; Berlin (Zentrales Geologisches Institut).

- (1995): Quaternary geology of the Altmark region. In: Ehlers, J., Kozarski, S. \& Gibbard, P. [Eds.]: Glacial deposits in North-East Europe: 473-484; Rotterdam.

Qurtzow, H.W. (1956): Die Terrassengliederung im niederrheinischen Tieflande. - Geol. en Mijnbouw, N.S., 18: 357-373; s'Gravenhage.

Richter, K. (1968): Klimatische Zyklen im norddeutschen Vereisungsgebiet. - Eiszeitalter u. Gegenwart, 19: 262-267; Öhringen.

RóżYCKI, S. (1972): Plejstocen Polski środkowej na tle przeszłości w górnym trzeciorzędzie. - $315 \mathrm{~S}$; Warszawa (PWN). 
Rühberg, N., Schulz, W., Bưlow, W.v., Müller, U., Krienke, H.-D., Bremer, F. \& Dann, T. (1995): V. Mecklenburg-Vorpommern. - In: BENDA, L. [Hrsg..]: Das Quartär Deutschlands: 95-115; Berlin/Stuttgart. Ruske, R. (1965): Zur Gliederung der Holstein- und Saalezeit im östlichen Harzvorland. - Eiszeitalter u. Gegenwart, 16: 88-96; Öhringen.

Sarnthein, M., Stremme, H. E. \& Mangini, A. (1986): The Holsteinian Interglaciation: time-stratigraphic position and correlation to stable-isotope stratigraphy of deep-sea sediments. - Quat. Res., 26: 283298; Washington.

SCHIRMER, W. (1990): Stauchmoränen und Aldekerker Platte. - In: Schirmer, W. [Hrsg.]: Rheingeschichte zwischen Mosel und Maas, Deuqua-Führer 1: 153164; Dormagen.

- [Ed.] (1995): Quaternary field trips in Central Europe (XIV. INQUA Congress August 3-10, 1995, Berlin, Germany). Volume 1: Regional field trips, Volume 2: Field trips on special topics, Volume 3: Field trips in Berlin and environs, Volume 4: Exkursionen in Berlin und Umland. - 1424 S.; München.

SCHLÜTER, G. (1978): Geschiebezählungen im Altmoränengebiet Schleswig-Holsteins. - Der Geschiebesammler, 12 (2/3): 3-12; Hamburg.

SCHOCH, W. H. (1993): Bestimmung einer Holzprobe aus dem Tranitzer Fluviatil des Tagebaus Jänschwalde als Quercus sp. = Eiche. - Briefl. Mitt. des Labors für quartäre Hölzer W. H. SCHOCH an Herrn Prof. Habbe, Erlangen, v. 11. Dez. 1993.

Schubert, G. (1979): Aufschlußbefunde zu einer jungpleistozänen Laufverlegung der Lausitzer Neiße (Nochtener Neißelauf) und zur Terrassengliederung. - Z. geol. Wiss., 7 (4): 463-477; Berlin.

Schwarcz, H.P., Grün, R., Latham, A.G., Mania, D. \& BRUNNACKER, K. (1988): The Bilzingsleben archeological site: New dating evidence. - Archeometry, 30: 5-17; Oxford.

Seifert, M. (1990a): Vegetationsgeschichtliche Entwicklung des Interglazials von Neumark-Nord. - Ethnogr-Archäol. Z., 31: 10-15; Berlin.

- (1990b): Ein Interglazial von Neumark-Nord (Geiseltal) im Vergleich mit anderen Interglazialvorkommen in der DDR. - Veröff. Landesmus. Vorgesch. Halle, 43: 131-143; Berlin.

STANKOWski, W. (2000): The Quaternary stratigraphy correlation of Great Poland Lowland and Central Germany. - Exkursionsf. u. Veröfftl. GGW, 209: 45; Berlin.

STeding, D. (1976): Das Quartär in der südöstlichen Oberlausitz. - In: Präger, F. [Hrsg.]: Exkursionsführer "Die glazigenen Bildungen im Südosten der DDR und ihre Beziehungen zum angrenzenden periglazialen Gebiet im Norden der CSSR", Ges. geol. Wiss. DDR: 6-12; Berlin.
Steinich, G. (1988): Neue Ergebnisse zur Quartärgeologie auf Nordrügen. - Exkursionsf. 35. Jahrestagg. GGW in Greifswald: 25-40; Berlin.

- (1992): Die stratigraphische Einordnung der RügenWarmzeit. - Z. geol. Wiss., 20 (1/2): 125-154; Berlin.

Stephan, H.-J. (1995): I. Schleswig-Holstein. - In: Benda, L. [Hrsg.]: Das Quartär Deutschlands: 1-22; Berlin/Stuttgart.

— , Kabel, C. \& Schlúter, G. (1983): Stratigraphical problems in the glacial deposits of Schleswig-Holstein. - In: EhLERs, J. [Hrsg.]: Glacial deposits in North-West Europe, 305-320; Rotterdam.

Stremme, H. E. (1989): Thermoluminescence Dating of the Pedostratigraphy of the Quaternary Period in NW Germany. - Geoderma, 45: 185-195; Amsterdam.

Striegler, R. \& Striegler, U. [Hrsg.] (1991): Eem von Schönfeld I. - Natur und Landschaft in der Niederlausitz, Sonderh.: 213 S.; Cottbus.

TGL 25232 (1971): Analyse des Geschiebebestandes quartärer Grundmoränen. - Fachbereichsstandard, Bl. 1-6, Staatssekr. f. Geologie, Berlin (2. erg. Aufl. 1980, Bearbeiter: A.G. CEPEK).

TGL 25 234/07 (1981): Stratigraphische Skala der DDR, Quartär. - Fachbereichsstandard, Ministerium f. Geologie, Berlin (Bearbeiter: A.G. СЕРек).

Thieke, H.-U. (1975): Schwermineralogische Kennzeichnung von fluviatilen spätelster-glazialen bis frühsaale-glazialen Ablagerungen im mittleren Teil der DDR. - Z. geol. Wiss., 3 (8): 1091-1101; Berlin.

Thоме, K. N. (1998): Einführung in das Quartär. - 288 S.; Berlin/Heidelberg.

Trembaczowski, J. (1961): Przyczynki do metodyki badan granulometryczno - petrograficznych utworów morenowych. - Annales UMCS, 16: 63-94; Lublin.

URBAN, B. (1983): Biostratigraphic correlation of the Kärlich Interglacial, Northwestern Germany. - Boreas, 12: 83-90; Oslo.

Wiegank, F. (1977): Paläomagnetische Datierung und Korrelation paläoklimatischer Ereignisse des Mittelund Jungpleistozäns. - Z. geol. Wiss., 5 (6): 705715; Berlin.

Woldstedt, P. (1927): Über die Ausdehnung der letzten Vereisung in Norddeutschland. - Sitzungsber. Preuß. Geol. Landesanst., (2): 115-119; Berlin.

- (1928): Die Gliederung des nordeuropäischen Diluviums. - Extract du Comte Rendu de la réunion géologique internat. à Copenhague: 209-224; Kopenhagen.

- (1962): Über die Gliederung des Quartärs und Pleistozäns. - Eiszeitalter u. Gegenwart, 13: 115-124; Öhringen. 
- \& Duphorn, K. (1974): Norddeutschland und angrenzende Gebiete im Eiszeitalter. - 3. Aufl.: 500 S.; Stuttgart.

Wolf, L. (1992): Buchbesprechung L. EIsSManN [Hrsg.] Die Eemwarmzeit und die frühe Weichseleiszeit im Saale-Elbe-Gebiet: Geologie, Paläontologie, Palökologie. - Z. geol. Wiss., 20 (1/2): 189-190; Berlin.

- , Steding, D. \& Schubert, G. (1992): Quartär. In: Ноth, K., Eilers, H., Fritzsche, H. [Hrsg.]: Geologische Übersichtskarte des Freistaates Sachsen 1:400 000. - Sächsisches Landesamt für Umwelt und Geologie; Freiberg.

ZAGWIJN, W. H. (1992): The beginning of the ice age in Europe and its major subdivisions. - Quart. Scince Rev., 11: 583-591; Oxford.

— \& Van Staalduinen, C. J. (1975): Toelichting bij geologische overzichtskaarten van Nederland (Explanation of general geological maps of the Netherlands). - Rijks Geologische Dienst: 134 S.; Haarlem.

ZANDSTRA, J.G. (1976): Sedimentpetrographische Untersuchungen des Geschiebelehms von Emmerschans (Drenthe, Niederlande) mit Bemerkungen über eine Typeneinteilung der Saale-Grundmoräne. - Eiszeitalter u. Gegenwart, 27: 30-52; Öhringen.

ZOLler, L. \& Karelin, P. (1993): Erste TL-Datierungen von Neumark-Nord und Bilzingsleben. - Vortrag zum V. Bilzingsleben-Kolloquium 1.-5.12.1993; Jena. 